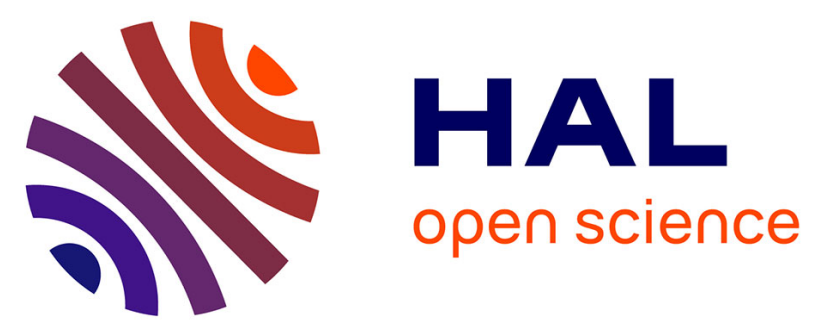

\title{
Influence of the lamination on the redundancy of a horizontally layered glass element and analysis of the debonding of the adhesive interlayer
}

\author{
Baghdad Krour, Fabrice Bernard, Samir Benyoucef, Bouazza Fahsi
}

\section{- To cite this version:}

Baghdad Krour, Fabrice Bernard, Samir Benyoucef, Bouazza Fahsi. Influence of the lamination on the redundancy of a horizontally layered glass element and analysis of the debonding of the adhesive interlayer. International Journal of Adhesion and Adhesives, 2016, 64, pp.116-127. 10.1016/j.ijadhadh.2015.10.006 . hal-01272156

HAL Id: hal-01272156

https://hal-univ-rennes1.archives-ouvertes.fr/hal-01272156

Submitted on 10 Feb 2016

HAL is a multi-disciplinary open access archive for the deposit and dissemination of scientific research documents, whether they are published or not. The documents may come from teaching and research institutions in France or abroad, or from public or private research centers.
L'archive ouverte pluridisciplinaire HAL, est destinée au dépôt et à la diffusion de documents scientifiques de niveau recherche, publiés ou non, émanant des établissements d'enseignement et de recherche français ou étrangers, des laboratoires publics ou privés. 


\title{
ACCEPTED MANUSCRIPT \\ INFLUENCE OF THE LAMINATION ON THE REDUNDANCY OF A HORIZONTALLY LAYERED GLASS ELEMENT AND ANALYSIS OF THE DEBONDING OF THE ADHESIVE INTERLAYER
}

\author{
Baghdad Krour ${ }^{1,4}$, Fabrice Bernard ${ }^{2 *}$, Samir Benyoucef ${ }^{3}$, Bouazza Fahsi ${ }^{3}$ \\ ${ }^{1}$ LMH, University Djillali Liabés, Sidi Bel Abbes, Algeria \\ ${ }^{2}$ LGCGM, UEB - INSA Rennes, France \\ ${ }^{3}$ LSMAGCTP, University Djillali Liabés, Sidi Bel Abbes, Algeria \\ ${ }^{4}$ University Mustapha Stambouli, Mascara, Algeria \\ *Corresponding author: Baghdad Krour, Laboratoire des matériaux et hydrologie (LM\&H), \\ Faculty of Technology, University Djillali Liabés of Sidi Bel Abbes, BP 89, Sidi Bel Abbes, \\ 22000, ALGERIA.
}

\begin{abstract}
It is now recognized that lamination enables to increase the redundancy of glass elements. This paper aims to quantify the possibilities of delamination between panes as well as the increase of redundancy for a horizontally layered glass element thanks to an analytical approach combined with a numerical modeling. From an analytical point of view, new procedures have been defined, taking into account the shear-lag effect as well as the mean curvature of the various adherents. The equilibrium of an infinitesimal element of the laminated structure has enabled to evaluate the interfacial stresses responsible for debonding phenomena. Based on this first approach and on the values of the interfacial stresses, a FE numerical simulation has been calibrated. This calibration is extended in two ways. First, the nonlinear behavior of the material is considered. A smeared crack approach is used to take into account the glass mechanical behavior. Then, a local debonding model involving the use of normal and shear springs is proposed at the interface between two glass panes. The mechanical behaviors of the springs are calibrated by simulating existing tension adhesion tests. Finally, by considering various structural cases, this work concludes that the debonding of the interface is a possibility and discusses its influence on the redundancy of the considered laminated structure.
\end{abstract}

\section{Keywords}

Laminated glass beam, interface stresses, hyper elastic behavior, shear-lag effect, finite element model, cohesive crack model 
1. Introduction

The brittleness of glass has largely contributed to give to this material a filling role (e.g in windows...), and has delayed its use as a structural material. However, glass has much more to offer in this regard due to its possibility to carry high compressive stresses and to its obvious aesthetical advantages.

It is now recognized that the strength, the robustness, and then the redundancy of glass elements can be considerably increased by laminating several panes to a composite action. As an interlayer, sheets of polyvinyl butyral (PVB) or Sentry Glass Plus ${ }^{\circledR}$ (SGP) are often used. Not only, does this interlayer enable the composite action to be developed, but also, when the first pane is broken, it may act as reinforcement for the remaining structure, leading to no catastrophic failure [1-3]. Preceding experimental research [4,5] has demonstrated that the SGP interlayer can be well exploited for bonding in laminated or hybrid glass beams. The shear strength and stiffness of the SGP interlayer is sufficient to transfer the forces between glasses to activate the reinforcement action once the glass is broken.

Laminated glass exhibits a complicated mechanical behavior because of the combination of a very stiff material (glass) and a very soft material (interlayer) [3,6]. A laminated glass pane is less stiff than a monolithic glass structure of the same dimensions, which leads to larger displacements. Furthermore, this increased structural integrity of a laminated glass element may be challenged by risks of debonding and/ or by the breakage of the interlayer. Hence, it is important, for a safe and cost-efficient strength design, that the structural behavior in terms of displacements and stress distributions is accurately determined since previous design methods, such as analytical formulas, do not provide sufficient information to determine accurate stress and determine the load-bearing capacity of laminated glass [1,7]. Thus an increasing number of analytical or numerical works deals with this challenge [6-12]. The work of Fröling and Persson [12] presents one of the most accurate numerical studies and proposes an efficient numerical method using specific modified solid shell element. This study presents also a sensitivity analysis on the number of degrees of freedom and thus on the mesh fineness.

However, these previous advanced works do not address the problem from the angle of the adhesive layer, and do not focus on the interfacial stresses, which are of prime importance in the analysis of the debonding possibilities.

This work investigates this new aspect. First, an accurate analytical prediction of the interfacial stresses in the adhesive layer, responsible for debonding, is presented. Such an analytical modeling is a fundamental tool for analyzing composite structures in general. Then, and based on this first study, a Finite Element (FE) computation with ABAQUS (Version 6.9) is performed to investigate the behavior of a laminated glass element. The paper focuses on the 
necessity to well capture the interfacial stresses and aims to provide information for an efficient FE analysis of laminated glass structures. Thus, by means of a local debonding model involving the use of normal and shear springs, the appearance of interface debonding in such structures is discussed, and its influence on the overall behavior of the glass element is analyzed.

\section{THEORETICAL BACKGROUND: ANALYTICAL ASSESSMENT OF INTERFACIAL STRESSES RESPONSIBLE FOR DEBONDING FAILURE}

\subsection{Objective}

Debonding failure in composite or hybrid structures is a consequence of too high shear and transverse normal stresses. Their accurate prediction is thus important for the design. Many studies have been conducted, both analytically and numerically, to predict these interfacial stresses. From this point of view, these studies have generally been conducted on strengthened Reinforced Concrete beams (among others: [13-18]), but some of them can be easily adapted to laminated glass structures.

Based on the solution given by Tsai [16], Tounsi [17] proposed a solution incorporating the effects of interfacial shear stresses on the strains in adherends, which were ignored by Smith \& Teng [13]. The computed interfacial stresses are found to be considerably smaller than those obtained by the models neglecting the shear strains of adherends. However, all the studies mentioned are based on the assumption that both adherends have the same curvature. Krour et al. [18] have developped an improved theory which releases the improper restriction of the equal curvatures of adherends.

Starting from this last improved analytical model, the present study investigates first the interfacial stresses in a simple laminated glass element composed of two horizontally layered glass panes (see Fig.1).

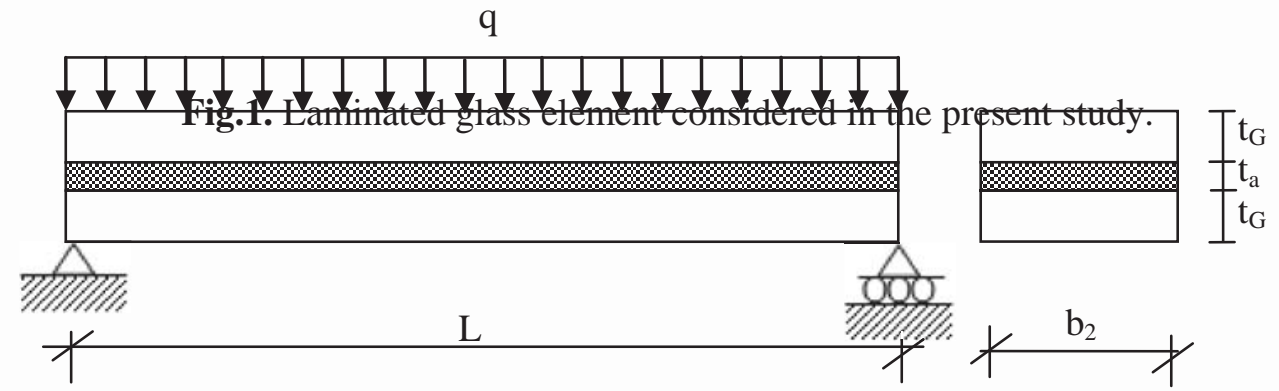




\subsection{Main assumptions}

The following assumptions are made:

- Simple beam theory is considered. Thus, the study is restricted to horizontally layered glass elements with a width $b_{2}$ significantly lower than the span (case of bridges for example). This assumption transforms a two-dimensional structural problem to only one-dimensional one.

- Glass is assumed to behave elastically, as well as the interlayer material. However the SGP Young modulus has two different values in function of the applied normal stress. This artifact is used to represent the hyperelastic behavior. This is one of the main novelties proposed in this paper: such a behavior has not been considered previously in the dedicated literature.

- Stresses in the adhesive layer do not change with the thickness unlike the model proposed by Rabinovitch \& Frostig [19] where the stresses vary across the adhesive thickness.

- Contrary to some existing studies, the assumption that both adherends have the same curvature is not used in the present investigation. The adhesive curvature is assumed to be the mean of the two adherends curvatures. This assumption is simpler than the one made by Rabinovitch \& Frostig [19] where higher order theory is used to describe the adhesive displacements.

- The component of shear deformation in the normal strain of the adherends has been included in the present theoretical analysis by assuming a parabolic distribution of shear stress across the thickness (shear-lag effect).

This assumption has been used in Tounsi et al [20] where the shear interfacial stress has to be continuous across the adherend section causing a lagging effect. The longitudinal displacement is assumed non-linear across the section following a cubic variation. This leads to a parabolic variation of the shear stress across the section.

- Since the section is bi-symmetrical, the neutral axis passes through the centroid, and the longitudinal normal stress is equal to $\sigma_{N}(x)=\frac{M_{z}(x)}{I_{e q}} y$ with $M_{\mathrm{z}}$ the applied bending moment and $I_{e q}=I_{1}+I_{2}+I_{a}+n S_{1}\left(\frac{t_{G}}{2}+\frac{t_{a}}{2}\right)^{2}+n S_{2}\left(\frac{t_{G}}{2}+\frac{t_{a}}{2}\right)^{2} \quad$ where $n=\frac{E_{a}}{E_{G}}$ where:

- $S_{1}, S_{2}, I_{1}$, and $I_{2}$ are respectively transversal sections and inertia moment of each adherend and Ia is the inertia moment of the adhesive

- $E_{\mathrm{a}}, E_{\mathrm{G}}$, are respectively elastic moduli of adhesive and glass pane.

$-y$ is the distances from the neutral axis; 


\subsection{Solutions procedure}

\subsubsection{Equilibrium of an infinitesimal element of a laminated glass floor}

Let consider an infinitesimal element of a laminated glass pane. This element is at the equilibrium under the effect of forces and stresses presented in figure 2.

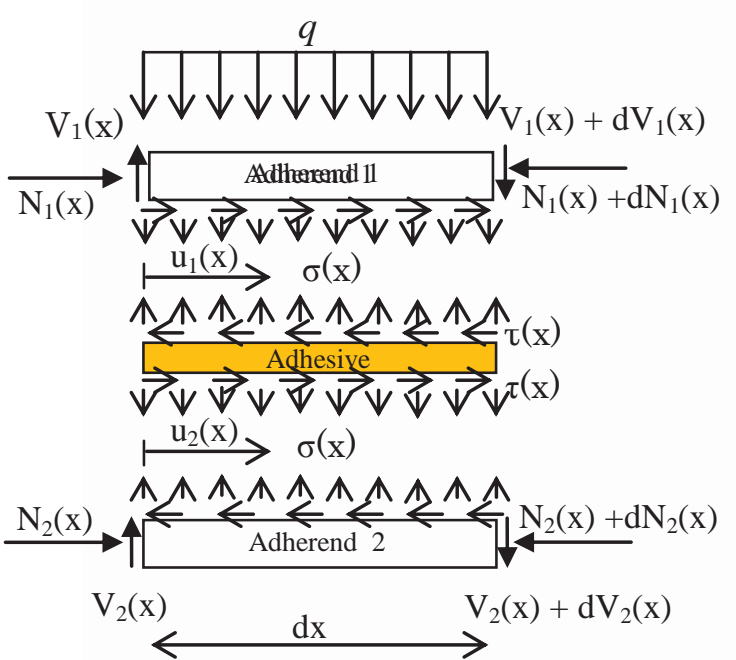

Forces
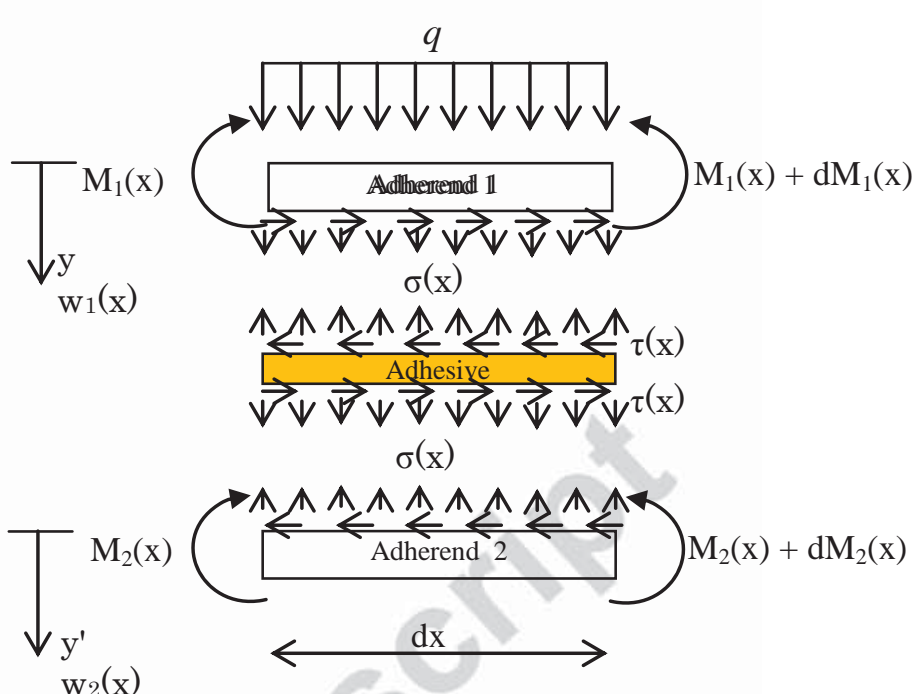

$\mathrm{w}_{2}(\mathrm{x})$

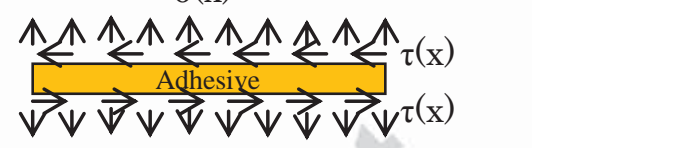

$\sigma(\mathrm{x})$

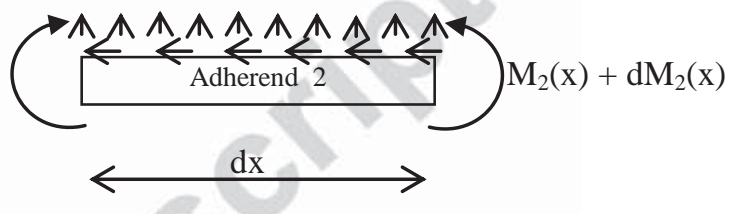

Bending moments

Fig.2. Forces in the infinitesimal element of a laminated glass plate.

The equilibrium of adherends 1 and 2 implies following equations:

Adherend $1: \frac{\partial M_{1}(x)}{\partial x}=V_{1}(x)-b_{2} y_{1} \tau(x)$ and $\frac{\partial V_{1}(x)}{\partial x}=-b_{2} \sigma(x)-q$

Adherend $2: \frac{\partial M_{2}(x)}{\partial x}=V_{2}(x)-b_{2} y_{2} \tau(x)$ and $\frac{\partial V_{2}(x)}{\partial x}=b_{2} \sigma(x)$

Consideration of the horizontal equilibrium gives:

$\frac{\partial N_{1}(x)}{\partial x}=b_{2} \tau(x)$

$$
\frac{\partial N_{2}(x)}{\partial x}=b_{2} \tau(x)
$$

where $b_{2}$ is the width of the bottom plate and $y_{1}$ and $y_{2}$ are the distances from the bottom of the adherend 1 and the top of the adherend 2 to their respective centroids.

Furthermore, applying relationship between curvature and moment for each adherend lead to: 
$\frac{\partial^{2} w_{1}(x)}{\partial x^{2}}=-\frac{M_{1}(x)}{E_{1} I_{1}}, \frac{\partial^{2} w_{2}(x)}{\partial x^{2}}=-\frac{M_{2}(x)}{E_{2} I_{2}}$

Based on the above-mentioned equilibrium equations, the governing differential equations for the deflection of adherends 1 and 2, expressed in terms of the interfacial shear and normal stresses, are given as follows:

Adherend $1: \frac{\partial^{4} w_{1}(x)}{\partial x^{4}}=\frac{1}{E_{1} I_{1}} b_{2} \sigma(x)+\frac{y_{1}}{E_{1} I_{1}} b_{2} \frac{\partial \tau(x)}{\partial x}+\frac{q}{E_{1} I_{1}}$

Adherend $2: \frac{\partial^{4} w_{2}(x)}{\partial x^{4}}=\frac{-1}{E_{2} I_{2}} b_{2} \sigma(x)+\frac{y_{2}}{E_{2} I_{2}} b_{2} \frac{\partial \tau(x)}{\partial x}$

\subsubsection{Stress distribution in the adhesive layer}

Since the displacements at the interfaces between the respective adherends and the adhesive layer are continuous, the mean strains in the adhesive layer can be expressed as:

$$
\begin{aligned}
& \varepsilon_{y}=\frac{\partial w(x, y)}{\partial y} \approx \frac{w_{2}(x)-w_{1}(x)}{t_{a}} \\
& \gamma_{x y}=\frac{\partial u(x, y)}{\partial y}+\frac{\partial w(x, y)}{\partial x} \approx \frac{u_{2}(x)-u_{1}(x)}{t_{a}}+\frac{1}{2}\left(\frac{\partial w_{2}(x)}{\partial x}+\frac{\partial w_{1}(x)}{\partial x}\right)
\end{aligned}
$$

where:

- $\varepsilon_{y}$ is the transversal normal strain (with the notations of figure 2) and $\gamma_{x y}$ is the shear distortion

- $u(\mathrm{x}, \mathrm{y})$ and $w(x, y)$ are the horizontal and vertical displacements, respectively, in the adhesive layer, as shown in figure 2;

- $u_{1}(x)$ and $u_{2}(x)$ are the longitudinal displacements at the bottom of adherend 1 and at the top of adherend 2, respectively;

- $w_{1}(\mathrm{x})$ and $w_{2}(\mathrm{x})$ are the vertical displacements of adherends 1 and 2, respectively;

$-t_{a}$ is the thickness of the adhesive layer.

In many previous works, the equality $\partial w(x, y) / \partial x=0$ is used, because the curvatures of the two adherends are assumed to be the same. It is apparent that these solutions do not consider the Poisson and transverse displacement effects. In this present study the mean curvature between the adherends is considered, leading to:

$$
\frac{\partial w(x, y)}{\partial x}=\frac{1}{2}\left(\frac{\partial w_{2}(x)}{\partial x}+\frac{\partial w_{1}(x)}{\partial x}\right)
$$

Starting from the linear relationships between stress and strain, interfacial shear and normal stresses can be expressed as follows: 
$\tau(x)=G_{a}\left[\frac{u_{2}(x)-u_{1}(x)}{t_{a}}+\frac{1}{2}\left(\frac{\partial w_{2}(x)}{\partial x}+\frac{\partial w_{1}(x)}{\partial x}\right)\right]$

$\sigma(x)=\frac{E_{a}}{t_{a}}\left[w_{2}(x)-w_{1}(x)\right]$

where $E_{a}$ et $G_{a}$ are the elastic moduli of the adhesive.

Regarding equation (12), the transversal normal stress is nothing but the consequence of the vertical separation between the adherends.

Then, equations (11) and (12) lead to:

$$
\tau(x)=G_{a}\left[\frac{u_{2}(x)-u_{1}(x)}{t_{a}}+\frac{\partial w_{2}(x)}{\partial x}-\frac{t_{a}}{2 E_{a}} \frac{\partial \sigma(x)}{\partial x}\right]
$$

Differentiating Equation (13) with respect to $x$ gives the shear stress expression:

$$
\frac{\partial \tau(x)}{\partial x}=\frac{G_{a}}{t_{a}}\left[\frac{\partial u_{2}(x)}{\partial x}-\frac{d u_{1}(x)}{\partial x}+t_{a} \frac{\partial^{2} w_{2}(x)}{\partial x^{2}}-\frac{t_{a}^{2}}{2 E_{a}} \frac{\partial^{2} \sigma(x)}{\partial x^{2}}\right]
$$

\subsubsection{Governing differential equations of interfacial stresses}

Taking into account all the three components of axial, bending and shear deformations (and thus the shear-lag effect), the normal strains at the bottom of adherend $1\left(\varepsilon_{1}\right)$ and at the top of adherend $2\left(\varepsilon_{2}\right)$ are given in [20]:

$$
\begin{gathered}
\varepsilon_{1}(x)=\frac{\partial u_{1}(x)}{\partial x}=\frac{y_{1}}{E_{1} I_{1}} M_{1}(x)-\frac{N_{1}(x)}{E_{1} S_{1}}+\frac{t_{1}}{4 G_{1}} \frac{\partial \tau(x)}{\partial x} \\
\varepsilon_{2}(x)=\frac{\partial u_{2}(x)}{\partial x}=\frac{-y_{2}}{E_{2} I_{2}} M_{2}(x)+\frac{N_{2}(x)}{E_{2} S_{2}}-\frac{5 t_{2}}{12 G_{2}} \frac{\partial \tau(x)}{\partial x}
\end{gathered}
$$

where:

$-N_{\mathrm{i}}(x)$ and $M_{\mathrm{i}}(x)$ are respectively axial forces and bending moment in each adherend,

- $y_{1}$ and $y_{2}$ are the distances from the top of adherend 1 and the bottom of the adherend 2 to their respective centroids;

- $S_{1}, S_{2}, I_{1}$, and $I_{2}$ are respectively transversal sections and inertia moment of each adherend;

- $E_{1}, E_{2}, G_{1}$, and $G_{2}$ are respectively elastic and shear moduli of each adherend;

- The last terms of both equations $\left(\frac{t_{1}}{4 G_{1}} \frac{\partial \tau(x)}{\partial x}\right)$ and $\left(-\frac{5 t_{2}}{12 G_{2}} \frac{\partial \tau(x)}{\partial x}\right)$ represent the component of the shear deformation (shear-lag effect). 
Using equations (1) to (4) and differentiating two times Equations (15) and (16), the third derivative of the horizontal displacement is expressed as:

$$
\begin{aligned}
& \frac{\partial^{3} u_{1}(x)}{\partial x^{3}}=\frac{y_{1}}{E_{1} I_{1}}\left(-b_{2} \sigma(x)-q-b_{2} y_{1} \frac{\partial \tau(x)}{\partial x}\right)-\frac{b_{2}}{E_{1} S_{1}} \frac{\partial \tau(x)}{\partial x}+\frac{t_{1}}{4 G_{1}} \frac{\partial^{3} \tau(x)}{\partial x^{3}} \\
& \frac{\partial^{3} u_{2}(x)}{\partial x^{3}}=\frac{-y_{2}}{E_{2} I_{2}}\left(b_{2} \sigma(x)-b_{2} y_{2} \frac{\partial \tau(x)}{\partial x}\right)+\frac{b_{2}}{E_{2} S_{2}} \frac{\partial \tau(x)}{\partial x}-\frac{5 t_{2}}{12 G_{2}} \frac{\partial^{3} \tau(x)}{\partial x^{3}}
\end{aligned}
$$

Differentiating two times equation (14) with respect to $x$ and using equations (6) and (7), on one hand, and (17) and (18), on the other hand, it can be obtained:

$\frac{\partial^{3} \tau(x)}{\partial x^{3}}=A_{1} \frac{\partial \tau(x)}{\partial x}+A_{2} \frac{\partial^{4} \sigma(x)}{\partial x^{4}}+A_{3} \sigma(x)+A_{4} q(x)$

Where: $\left\{\begin{array}{l}A_{1}=K\left(\frac{y_{1}^{2} b_{2}}{E_{1} I_{1}}+\frac{y_{2}^{2} b_{2}}{E_{2} I_{2}}+\frac{b_{2}}{E_{1} A_{1}}+\frac{b_{2}}{E_{2} A_{2}}+\frac{t_{a} b_{2} y_{2}}{E_{2} I_{2}}\right) \\ A_{2}=-K \frac{t_{a}^{2}}{2 E_{a}} \\ A_{3}=K\left(\frac{y_{1} b_{2}}{E_{1} I_{1}}-\frac{y_{2} b_{2}}{E_{2} I_{2}}-\frac{t_{a} b_{2}}{E_{2} I_{2}}\right) \\ A_{4}=K \frac{y_{1}}{E_{1} I_{1}} \\ K=\frac{1}{\left(\frac{t_{a}}{G_{a}}+\frac{t_{1}}{4 G_{1}}+\frac{5 t_{2}}{12 G_{2}}\right)}\end{array}\right.$

Otherwise, inserting equations (6) and (7) in the fourth derivative of the interfacial transversal normal stress obtained by equation (12), enables to express the following governing differential equation for the interfacial transversal normal stress:

$\frac{\partial^{4} \sigma(x)}{\partial x^{4}}+B_{1} \sigma(x)+B_{2} \frac{\partial \tau(x)}{\partial x}+B_{3} q=0$

Where: $\left\{\begin{array}{l}B_{1}=\frac{E_{a} b_{2}}{t_{a}}\left(\frac{1}{E_{1} I_{1}}+\frac{1}{E_{2} I_{2}}\right) \\ B_{2}=\frac{E_{a} b_{2}}{t_{a}}\left(\frac{y_{1}}{E_{1} I_{1}}-\frac{y_{2}}{E_{2} I_{2}}\right) \\ B_{3}=\frac{E_{a}}{t_{a}} \frac{1}{E_{1} I_{1}}\end{array}\right.$ 


\section{ACCEPTED MANUSCRIPT}

The two differential equations (19) and (21) are coupled. However at least one of them may be rearranged.

Indeed, equation (20) leads to:

$\frac{\partial^{4} \sigma(x)}{\partial x^{4}}=-B_{1} \sigma(x)-B_{2} \frac{\partial \tau(x)}{\partial x}-B_{3} q$

Then, the insertion of equation (23) into equation (19) gives:

$\frac{\partial^{3} \tau(x)}{\partial x^{3}}=\left(A_{1}-A_{2} B_{2}\right) \frac{\partial \tau(x)}{\partial x}+\left(A_{3}-A_{2} B_{1}\right) \sigma(x)+\left(A_{4}-A_{2} B_{3}\right) q(x)$

Equation (24) leads to:

$\sigma(x)=\frac{1}{\left(A_{3}-A_{2} B_{1}\right)}\left[\frac{\partial^{3} \tau(x)}{\partial x^{3}}-\left(A_{1}-A_{2} B_{2}\right) \frac{\partial \tau(x)}{\partial x}-\left(A_{4}-A_{2} B_{3}\right) q(x)\right]$

Substituting Equation (25) into Equation (20) gives:

$$
\begin{gathered}
\frac{\partial^{7} \tau(x)}{\partial x^{7}}-\left(A_{1}-A_{2} B_{2}\right) \frac{\partial^{5} \tau(x)}{\partial x^{5}}+B_{1} \frac{\partial^{3} \tau(x)}{\partial x^{3}}+\left[B_{2}\left(A_{3}-A_{2} B_{1}\right)-B_{1}\left(A_{1}-A_{2} B_{2}\right)\right] \frac{\partial \tau(x)}{\partial x} \\
-\left(A_{4}-A_{2} B_{3}\right) \frac{\partial^{4} q(x)}{\partial x^{4}}+\left[B_{3}\left(A_{3}-A_{2} B_{1}\right)-B_{1}\left(A_{4}-A_{2} B_{3}\right)\right] q(x)=0
\end{gathered}
$$

\subsubsection{General solutions}

For simplicity, the general solutions presented below are limited to the cases of loads which are either concentrated or uniformly distributed over a part or the entire span of the beam, or both. For such loads, the second and higher-order derivatives are zero. Then, Equation (26) can be rewritten as follows:

$$
\begin{aligned}
\frac{\partial^{7} \tau(x)}{\partial x^{7}}+ & \left(A_{2} B_{2}-A_{1}\right) \frac{\partial^{5} \tau(x)}{\partial x^{5}}+B_{1} \frac{\partial^{3} \tau(x)}{\partial x^{3}}+\left[B_{2}\left(A_{3}-A_{2} B_{1}\right)-B_{1}\left(A_{1}-A_{2} B_{2}\right)\right] \frac{\partial \tau(x)}{\partial x} \\
& +\left[B_{3}\left(A_{3}-A_{2} B_{1}\right)-B_{1}\left(A_{4}-A_{2} B_{3}\right)\right] q(x)=0
\end{aligned}
$$

The general solution to Equation (27) is thus given by:

$$
\tau(x)=A_{5} q x+C_{1} e^{\lambda x}+C_{2} e^{-\lambda x}+C_{3}
$$

Where:

$$
A_{5}=-\left(\frac{A_{4} B_{1}-A_{3} B_{3}}{A_{1} B_{1}-A_{3} B_{2}}\right), \quad \lambda^{2}=\frac{B_{1} A_{1}-B_{2} A_{3}}{B_{1}}
$$

In order to obtain Equation (28), it has been assumed that $d^{5} \tau / d x^{5}=0$. Indeed this derivative has generally a negligible effect on the final solution [21]. 
The general solution of Equation (21) may now be obtained. It is given by:

$$
\begin{aligned}
& \sigma(x)=e^{-\beta x}\left[D_{1} \cos (\beta x)+D_{2} \sin (\beta x)\right]+e^{\beta x}\left[D_{3} \cos (\beta x)+D_{4} \sin (\beta x)\right] \\
& -n_{1} \frac{\partial \tau(x)}{\partial x}-n_{2} q
\end{aligned}
$$

For large values of $x$, it is assumed that the normal and shear stresses approach zero, consequently :

$C_{1}=D_{3}=D_{4}=0$.

The general solutions become thus:

$$
\begin{aligned}
& \tau(x)=A_{5} q x+C_{1} e^{\lambda x}+C_{3} \\
& \sigma(x)=e^{-\beta x}\left[D_{1} \cos (\beta x)+D_{2} \sin (\beta x)\right]-n_{1} \frac{\partial \tau(x)}{\partial x}-n_{2} q \\
& \text { With: }\left\{\begin{array}{l}
\beta=\sqrt[4]{\frac{B_{1}}{4}} \\
n_{1}=\frac{y_{1} E_{2} I_{2}-y_{2} E_{1} I_{1}}{E_{1} I_{1}+E_{2} I_{2}} \\
n_{2}=\frac{E_{2} I_{2}}{b_{2}\left(E_{1} I_{1}+E_{2} I_{2}\right)}
\end{array}\right.
\end{aligned}
$$

\subsection{Results and discussion}

\subsubsection{Application to an existing case}

The dimensions of the laminated glass structure investigated here are given in Table 1. Two interlayers are considered in this part of the study: PVB and SGP. The PVB interlayer is assumed to be fully elastic whereas SGP has a hyperelastic behavior. As previously explained an artifact is used to take into account such a behavior: the Young modulus of this material has two different values in function of the applied normal stress. Furthermore, a uniformly distributed load of $6 \mathrm{KN} / \mathrm{m}$ is considered. 
Table 1. Geometrical and material data.

\begin{tabular}{|c|c|c|c|c|c|}
\hline Adherends & $\begin{array}{c}\text { Length L } \\
(\mathrm{mm})\end{array}$ & $\begin{array}{c}\text { Width } \mathrm{b} \\
(\mathrm{mm})\end{array}$ & $\begin{array}{c}\text { Thickness } \mathrm{t} \\
(\mathrm{mm})\end{array}$ & $\mathrm{E}(\mathrm{GPa})$ & $\mathrm{v}$ \\
\hline Glass \#1 & $\mathrm{L}=2000$ & $\mathrm{~b}_{1}=150$ & $\mathrm{t}_{\mathrm{G}}=9.5$ & $\mathrm{E}_{1}=70$ & 0.22 \\
\hline $\begin{array}{c}\text { Adhesive } \\
(\text { SGP) }\end{array}$ & $\mathrm{L}_{\mathrm{a}}=2000$ & $\mathrm{~b}_{\mathrm{a}}=150$ & $\mathrm{t}_{\mathrm{a}}=1.5$ & $\begin{array}{c}\mathrm{E}_{\mathrm{a}}=0.165 \text { if } \sigma<20 \mathrm{Mpa} ; \\
\mathrm{E}_{\mathrm{a}}=0.01 \text { else }\end{array}$ & 0.5 \\
\hline $\begin{array}{c}\text { Adhesive } \\
\text { (PVB) }\end{array}$ & $\mathrm{L}_{\mathrm{a}}=2000$ & $\mathrm{~b}_{\mathrm{a}}=150$ & $\mathrm{t}_{\mathrm{a}}=1.5$ & $\mathrm{E}_{\mathrm{a}}=0.004$ & 0.5 \\
\hline Glass \#2 & $\mathrm{L}=2000$ & $\mathrm{~b}_{2}=150$ & $\mathrm{t}_{\mathrm{G}}=9.5$ & $\mathrm{E}_{2}=70$ & 0.22 \\
\hline
\end{tabular}

The mechanical characteristics of SGP correspond to those obtained at room temperature and for a loading rate of $5 \mathrm{~mm} / \mathrm{min}$ [22]

The theoretical expressions that have been obtained in this study enable to investigate the effect of several parameters, such as the shear-lag effect, the assumptions of the different curvatures between adherends, or the adhesive and glass thicknesses on the interfacial stresses. Indeed, such results have undeniable constructive interests.

Moreover, these results, which are obtained with a limited number of assumptions, constitute an important database for any modeling attempts (see section 3).

\subsubsection{Influence of the shear-lag effect and of the mean curvature of the adherends}

Interfacial shear stresses in function of the distance from the support are presented in figure 3a. A comparison with the results of Smith \& Teng [13] and Tounsi et al. [20] is also provided showing respectively the influence of the shear-lag effect and of the assumption of the different curvatures between both adherends. It appears obvious that, in the present case, this last assumption increases the debonding risks whereas the shear-lag effect appears to be negligible. Indeed, in the Smith \& Teng [13] model, the shear-lag effect is neglected unlike the Tounsi et al. [20] model. The figure 3 a shows that the two models give exactly the same results, which means that the shear-lag effect has no influence on the final result of the shear and normal interfacial stresses.

However, the present model taking into account the difference between the adherend's curvatures gives a high level of interfacial shear stress which means that for such thin structural elements, the possibility of a difference in the curvatures of the two glass panes should therefore be taken into account. 


\section{ACCEPTED MANUSCRIPT}

On the contrary, interfacial normal stresses (Fig. 3 b) are not influenced by these two assumptions. Their maximal value is obtained in front of the support and decreases rapidly to be equal to about zero at $\mathrm{x}=70 \mathrm{~mm}$.

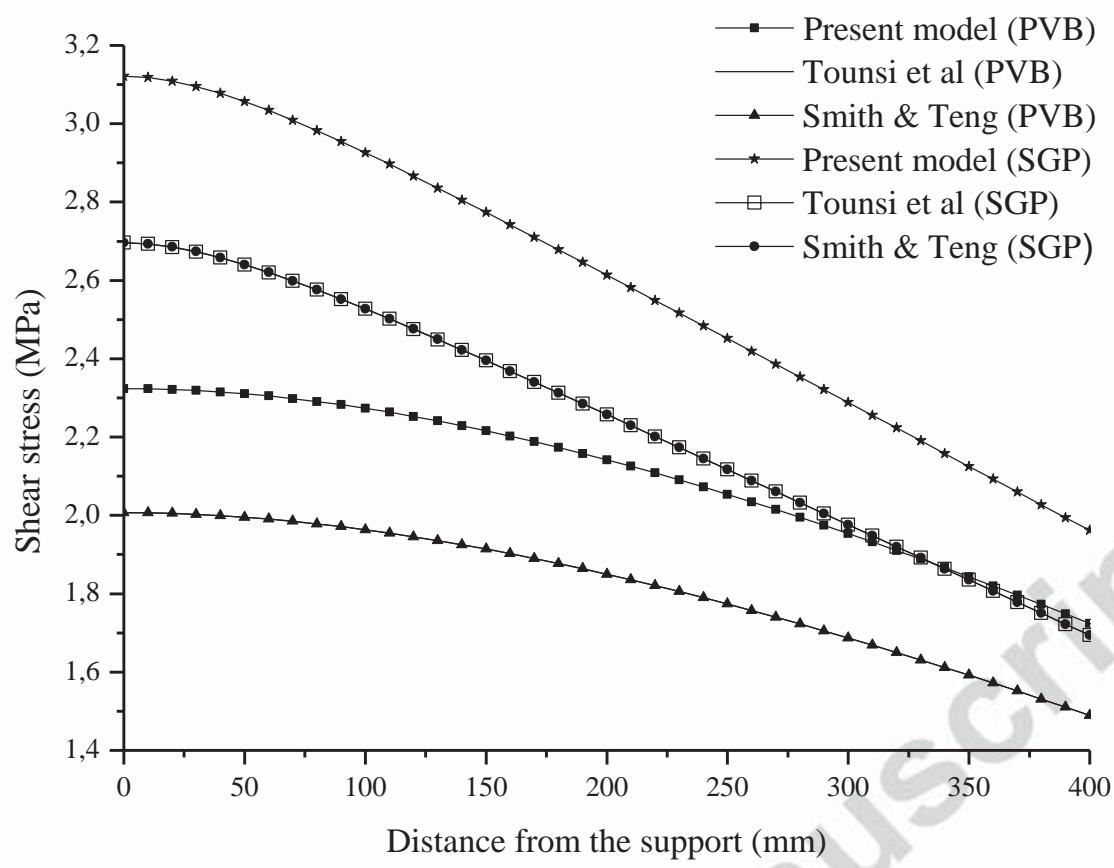

(a)

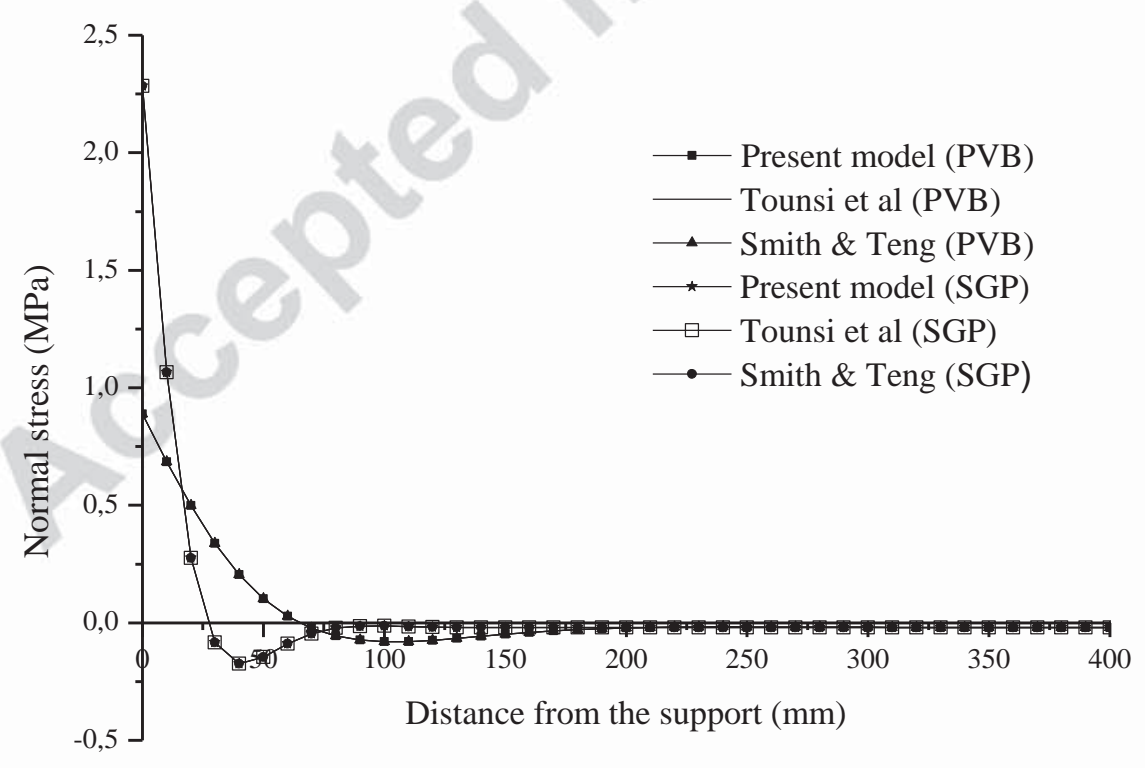

b) 


\section{ACCEPTED MANUSCRIPT}

Fig. 3. Interfacial shear (a) and transversal normal (b) stress with respect to the distance from the support. Influence of the shear-lag effect and of the different curvatures between adherends.

In the following studies, only SGP interlayer is considered in aim to show the influence of the hyperelastic behavior on the interfacial stresses

\subsubsection{Influence of the adhesive thickness}

The adhesive thickness does not play a significant role on the intensity of the interfacial stresses, as revealed by figures $4 a$ and $b$.

In function of the adhesive thickness, a small shift can be seen in the evolution of the interfacial shear stress. It denotes the decrease of the Young's modulus of the adhesive layer due to its hyperelastic behavior.

Thus only the existence and the position of the shift in shear stresses is influenced by this parameter.

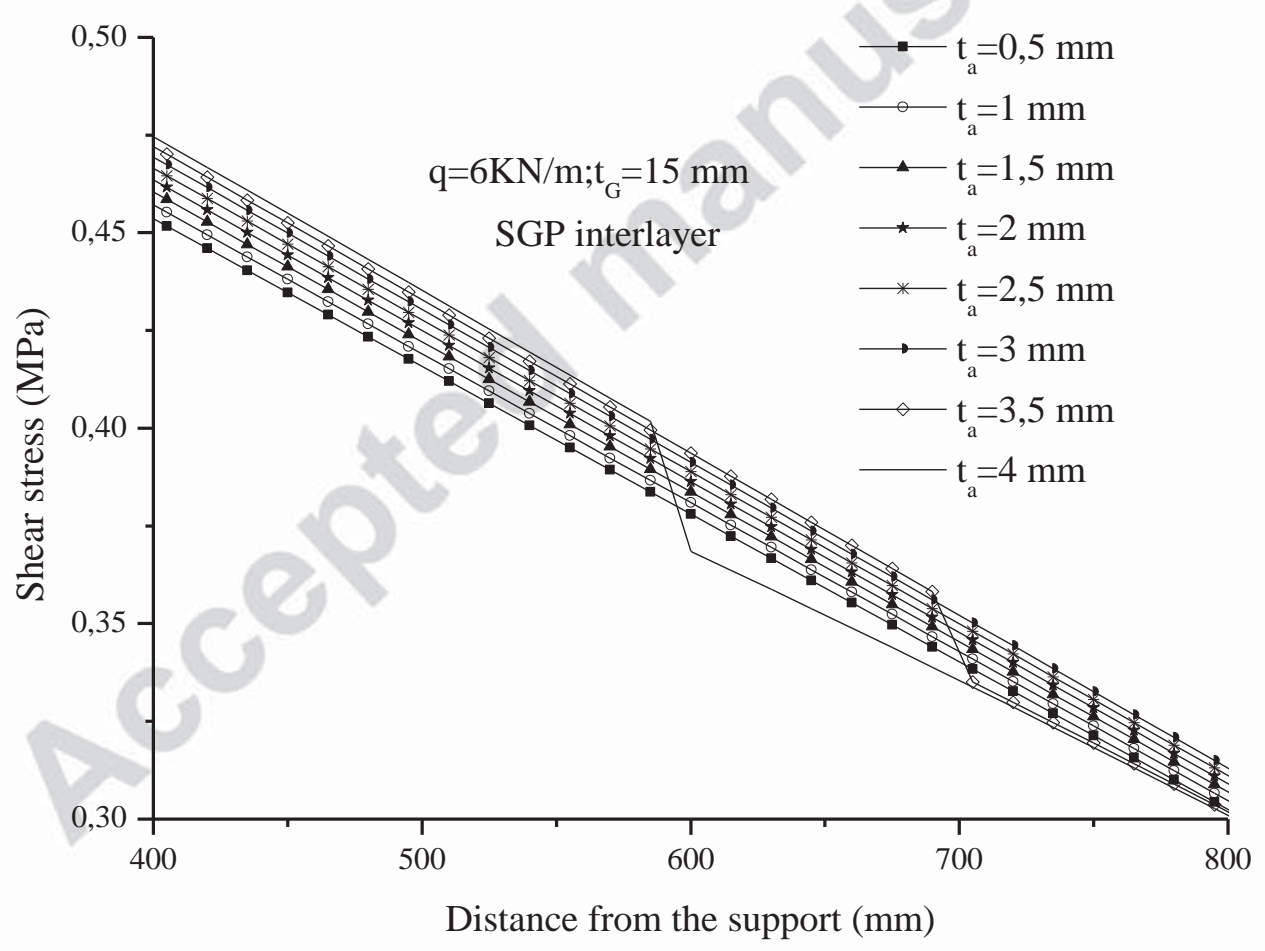

(a) 


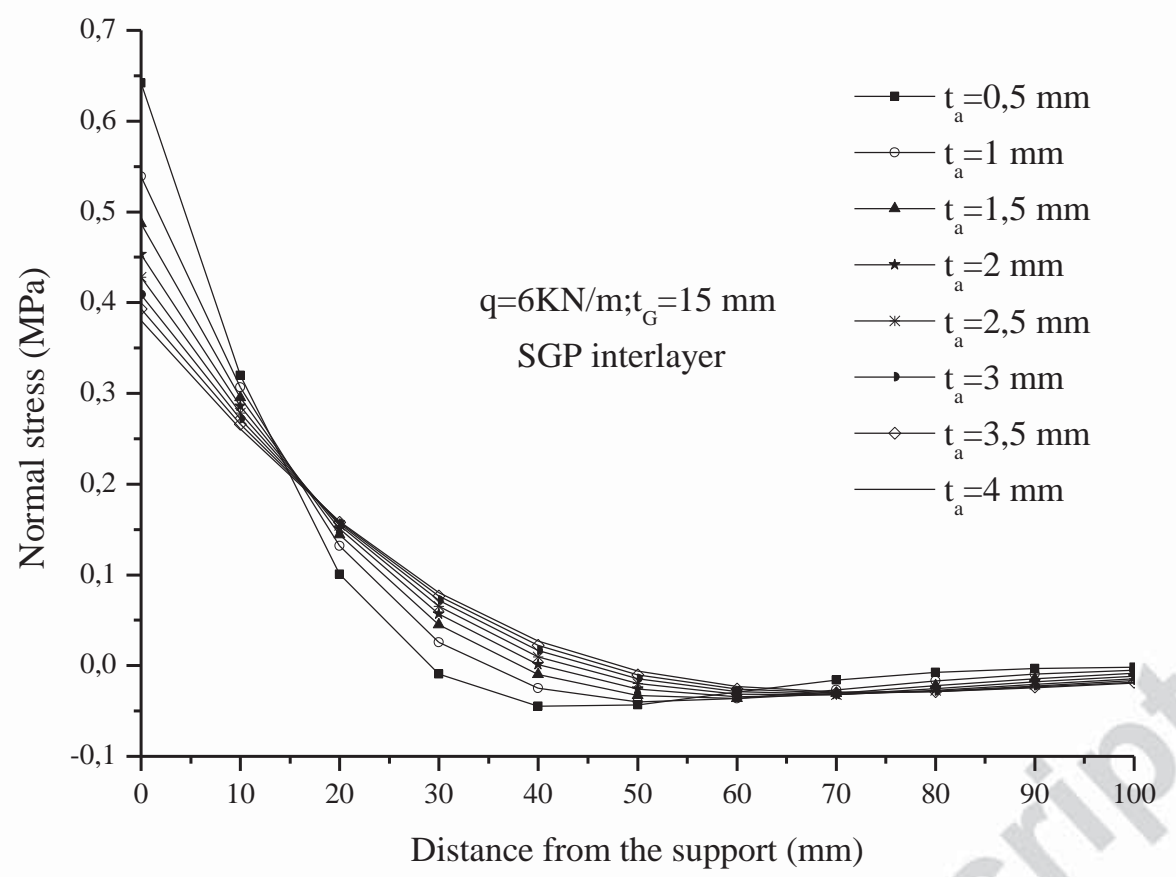

(b)

Fig.4. Interfacial shear (a) and normal (b) stresses with respect to the distance from the support. Influence of the adhesive thickness.

\subsubsection{Influence of the glass thickness}

In this part of the study, the influence of the glass thickness on the interfacial stresses is investigated. This parameter is obviously of prime importance and for thin glass plates $\left(\mathrm{t}_{\mathrm{G}}<5\right.$ $\mathrm{mm}$ ) the risks of debonding are really significant as the normal and shear interfacial stresses reach critical values (Fig. $5 \mathrm{a}$ and b), which are around 1-2 MPa ([23-24]). 


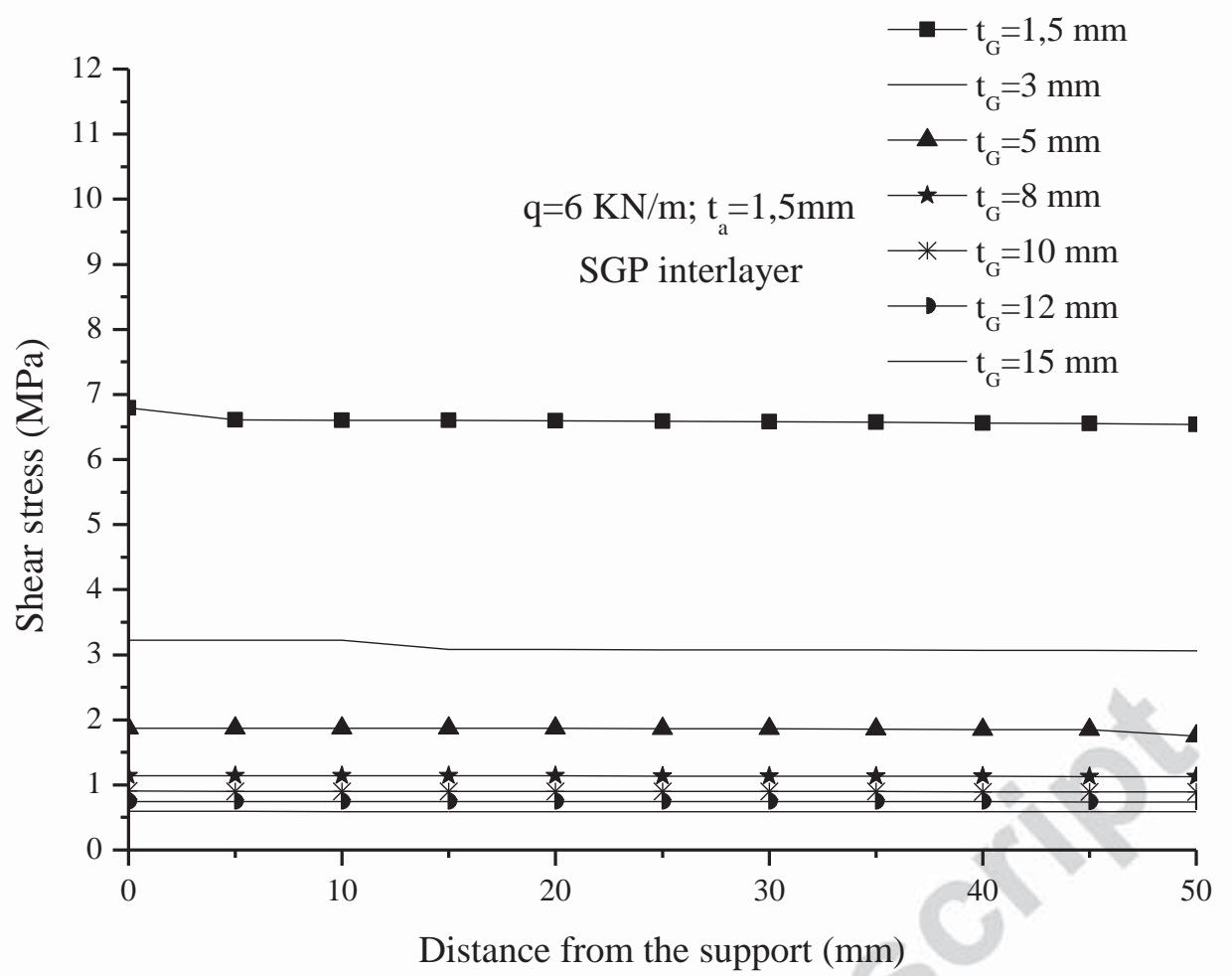

(a)

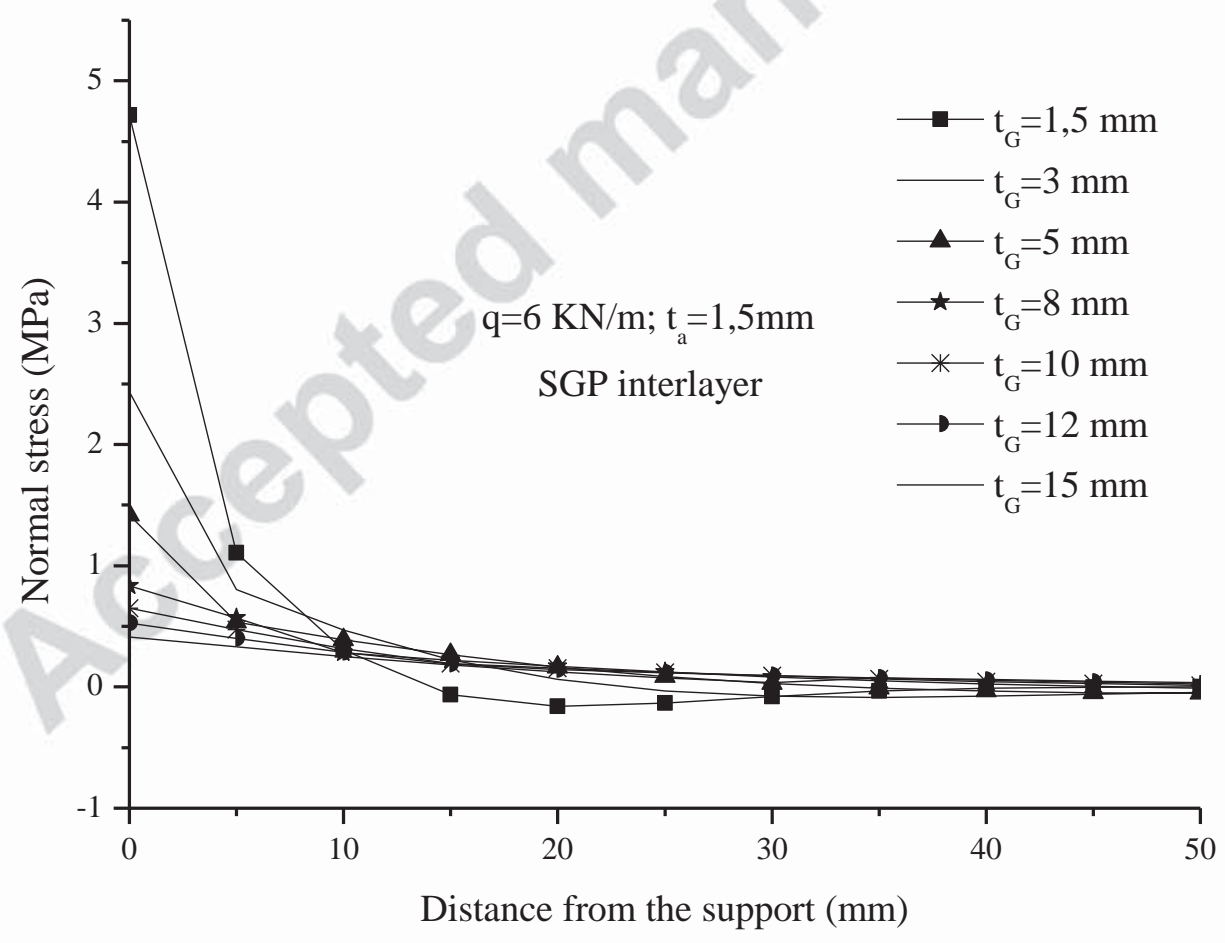

(b)

Fig.5. Interfacial shear (a) and normal (b) stresses with respect to the distance from the support. Influence of the glass thickness. 


\section{DEBONDING FAILURE}

\subsection{Determination of the optimal mesh}

\subsubsection{Methodology and main hypotheses}

In absence of experimental data, especially concerning interfacial stresses, analytical results can be used to develop a FE modeling. The determination of the stresses singularities near to the edges or to the corners has been extensively studied in the literature leading to the development of fracture mechanics solutions. Indeed, various researchers have studied material mismatch parameters and the stress singularities at interface corners/wedges/cracks since the pioneering work described by Williams M.L [25-26]. By contrast, the present study is a particular case of this vast problem and concerns the determination of the stresses singularities in adhesive layers. In adhesively bonded joints, a 2D analysis in plane conditions is often preferred. Despite 3D effects such as the lateral deformation, (Adams and Peppiatt [27]) and the anticlastic bending Adams and Davies [28] ; Gonçalves et al. [29], various studies have shown that 2D analyses give accurate enough results (Adams et al.[30]; Adams and Davies [31]).

Thus, based on this analytical approach presented in section 2 and on the values of the interfacial stresses, a FE numerical simulation, with the FE package Abaqus, has been calibrated. A 2D model, such as in the analytical study, has been considered for this analysis. That enables to refine the mesh, especially in the adhesive layer in order to capture accurately the interfacial stresses. Such equivalent sensitivity analysis to determine the optimal mesh has been previously performed in [32-34]. In this previous works devoted to the analysis of debonding in $\mathrm{RC}$ beams strengthened with composite plate, the variations of interfacial normal and shear stresses have been determined as the height of the smallest element has been reduced. The same methodology is now applied for the kind of structure (glass floor) studied in this paper. Results might be different since the lower plate is now concerned by the boundary condition, on the contrary to the case of the strengthening plate.

In the following simulation, the contact between all parts of the model is supposed to be perfect ("tie" contact).

The PVB interlayer is considered in the following of the study. A pinned-pinned horizontally laminated glass structure with a uniformly distributed load of $2 \mathrm{kN} / \mathrm{m}$. All the dimensions are provided in Table 2. In this part of the study, materials are considered as elastic. Elastic parameters are also reminded in Table 2. The interlayer material is assumed to be incompressible and consequently its Poisson ratio is taken equal to 0.5. 


\section{ACCEPTED MANUSCRIPT}

Four-node linear quadrilateral plane stress elements (CPS4R) are used to model the two glass panes as well as the interlayer. As in [35] all of the parts of the beam are explicitly modeled. Only half of the beam is modeled due the symmetry and a particularly fine mesh is employed for the adhesive layer and at the end of the panes to obtain accurate results. The existence of points of singularity presents a challenge to the choice of a suitable finite element mesh as the stresses at these points increase with the mesh refinement. Figure 6 presents a zoom of the mesh (element minimum size: $0.2 \mathrm{~mm}$ ) at the end of the floor. In the longitudinal direction of the structure, a graded mesh has been used starting with an aspect ratio of 1 for the minimum height elements.

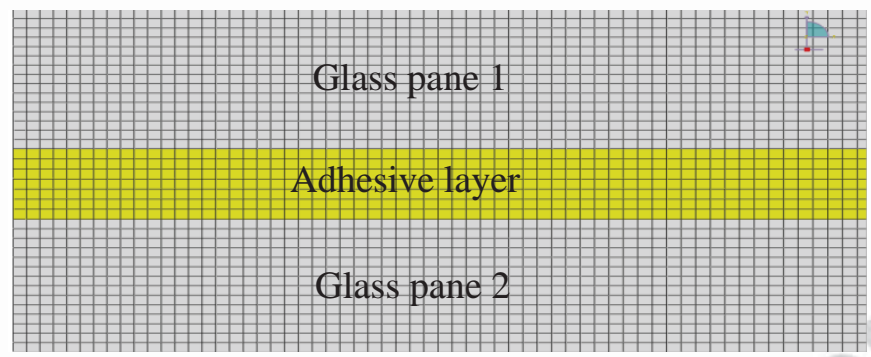

Fig. 6. Optimized mesh. Zoom on the edge.

Table 2. Geometrical and material proprieties for the mesh optimization procedure

\begin{tabular}{|c|c|c|c|c|c|}
\hline Materials & Length $(\mathrm{mm})$ & Width $(\mathrm{mm})$ & Depth $(\mathrm{mm})$ & $\mathrm{E}(\mathrm{GPa})$ & $v$ \\
\hline Glass 1 & $\mathrm{~L}=2000$ & $\mathrm{~b}_{1}=150$ & $\mathrm{t}_{\mathrm{G}}=9.5$ & 70 & 0.22 \\
\hline Adhesive layer & $\mathrm{L}_{\mathrm{a}}=2000$ & $\mathrm{~b}_{\mathrm{a}}=150$ & $\mathrm{t}_{\mathrm{a}}=1.5$ & 0.004 & 0.5 \\
\hline Glass 2 & $\mathrm{L}=2000$ & $\mathrm{~b}_{2}=150$ & $\mathrm{t}_{\mathrm{G}}=9.5$ & 70 & 0.22 \\
\hline
\end{tabular}

The variations of interfacial normal and shear stresses at the interfaces between adhesive and upper glass pane and between adhesive and lower glass pane, but also at the mid-adhesive section are determined as the height of the smallest element has been reduced from 1.5 to 0.1 $\mathrm{mm}$. The stresses reported in each of the following figures are those extrapolated by the FE analysis at the nodes of the finite elements.

\subsubsection{Discussions about the sensitivity analysis on the mesh size}

Results are plotted in figures 7 a,b,c (shear stresses) and 8 a,b,c (transversal normal stresses). The presentation of these results focuses on the edge area since beyond a distance of $5 \mathrm{~mm}$ the interfacial stresses obtained with the various meshes tend towards the same values (except for normal stresses at the upper adhesive interface). 


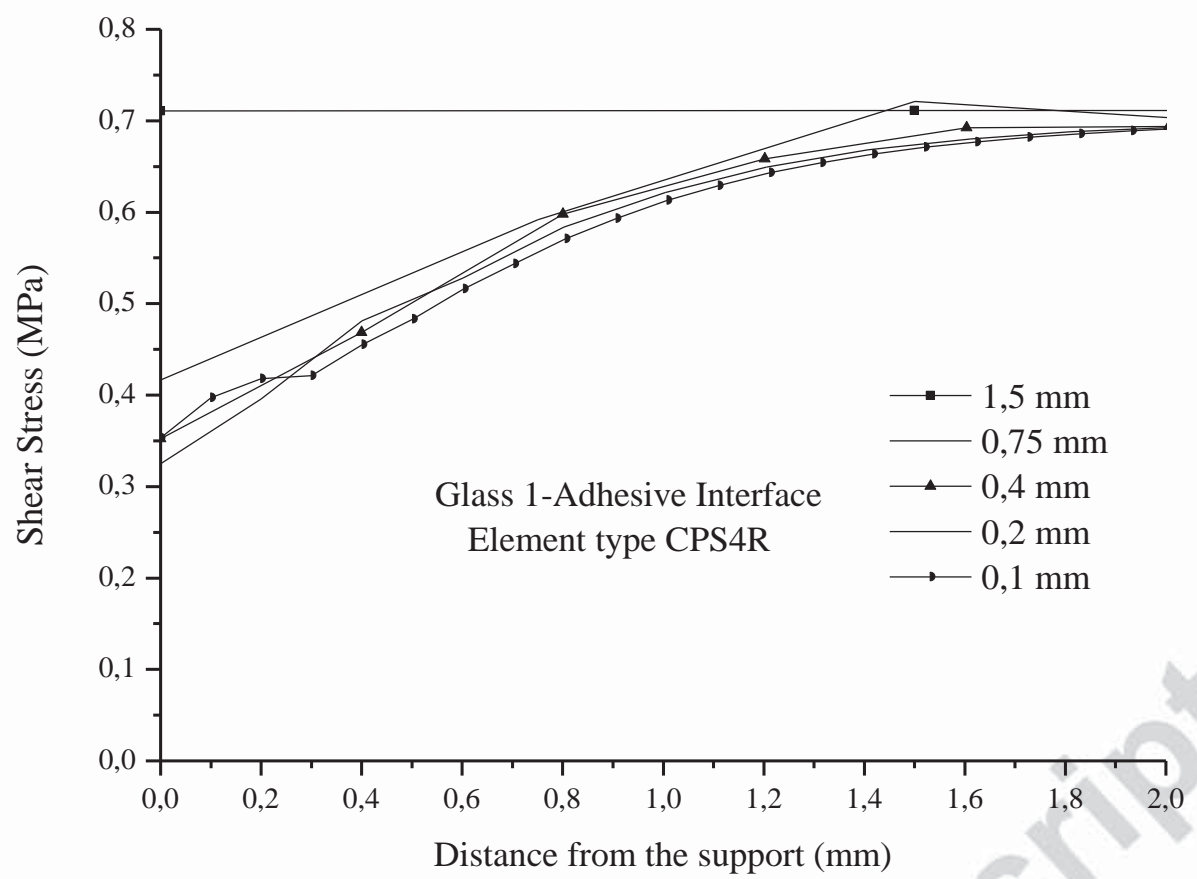

(a)

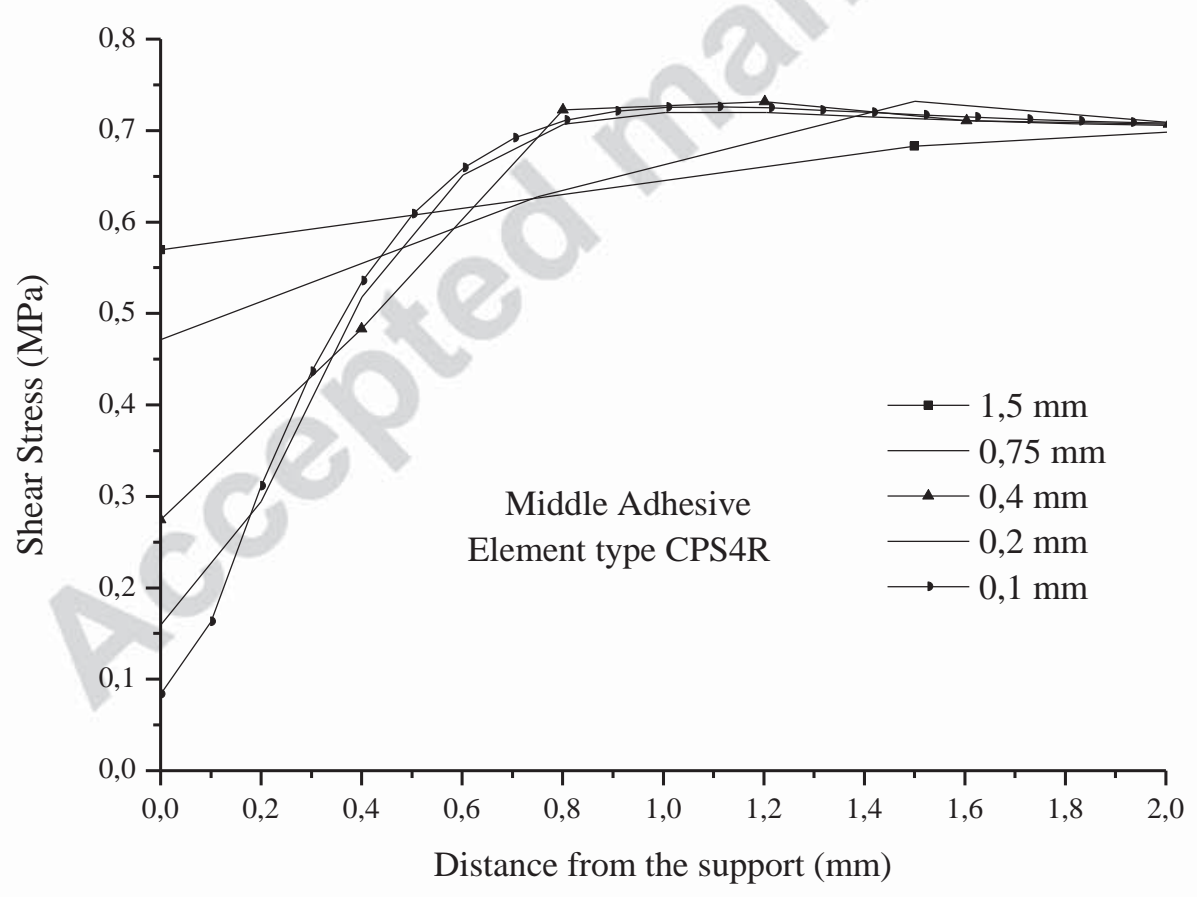

(b) 


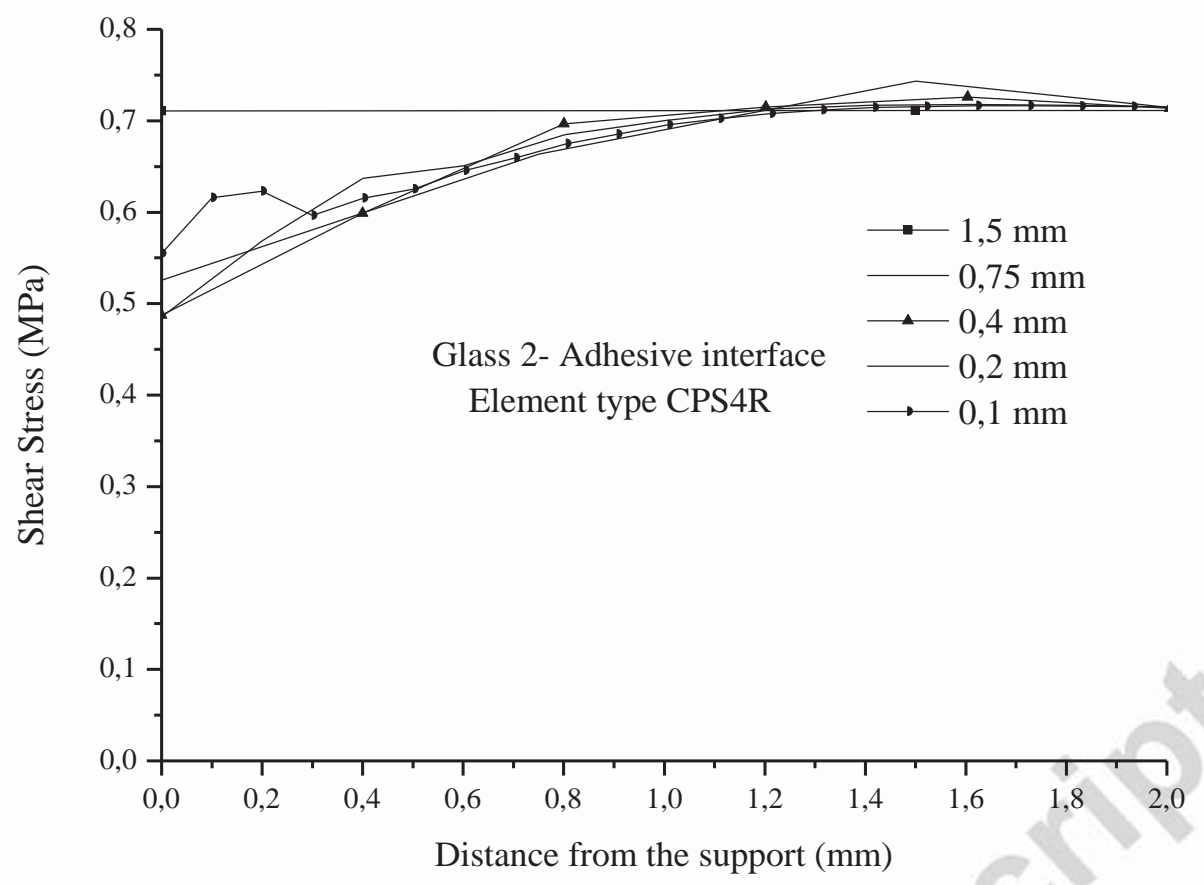

(c)

Fig.7. Interfacial shear stress with respect to the distance from the support for various minimal finite elements sizes (a) at the upper glass-adhesive interface, (b) at the mid-adhesive section, (c) at the lower glass-adhesive interface. 


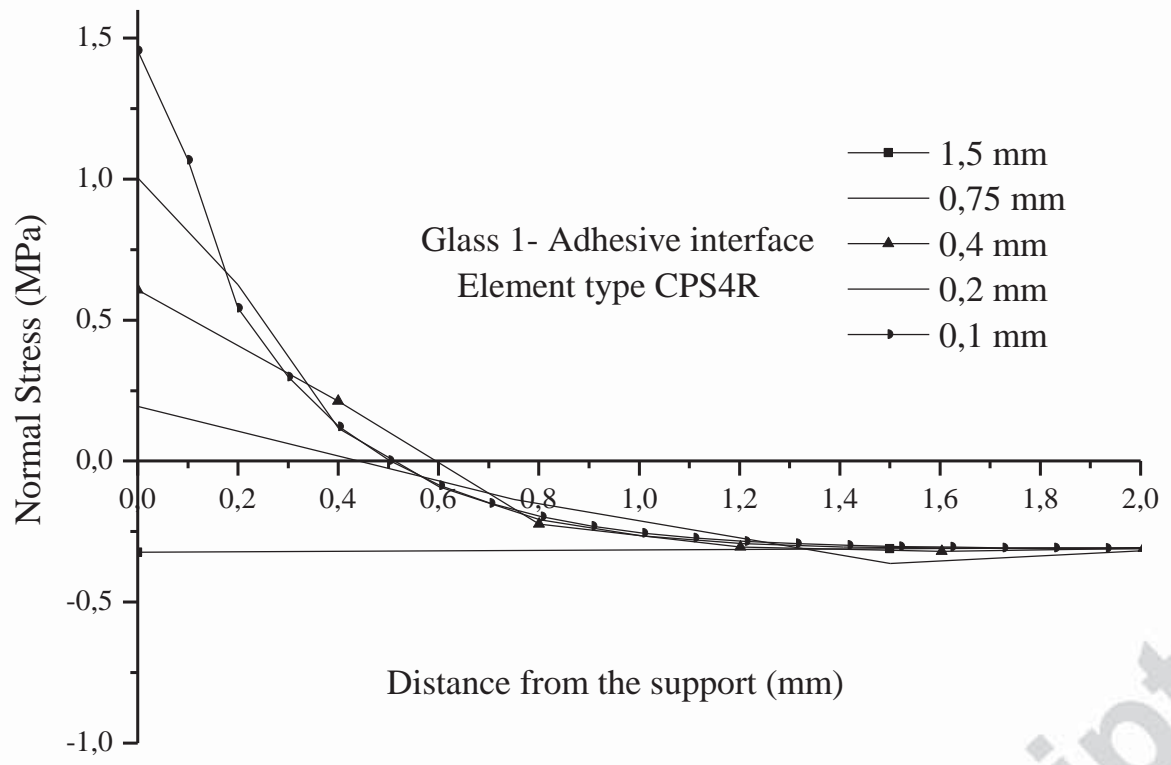

(a)

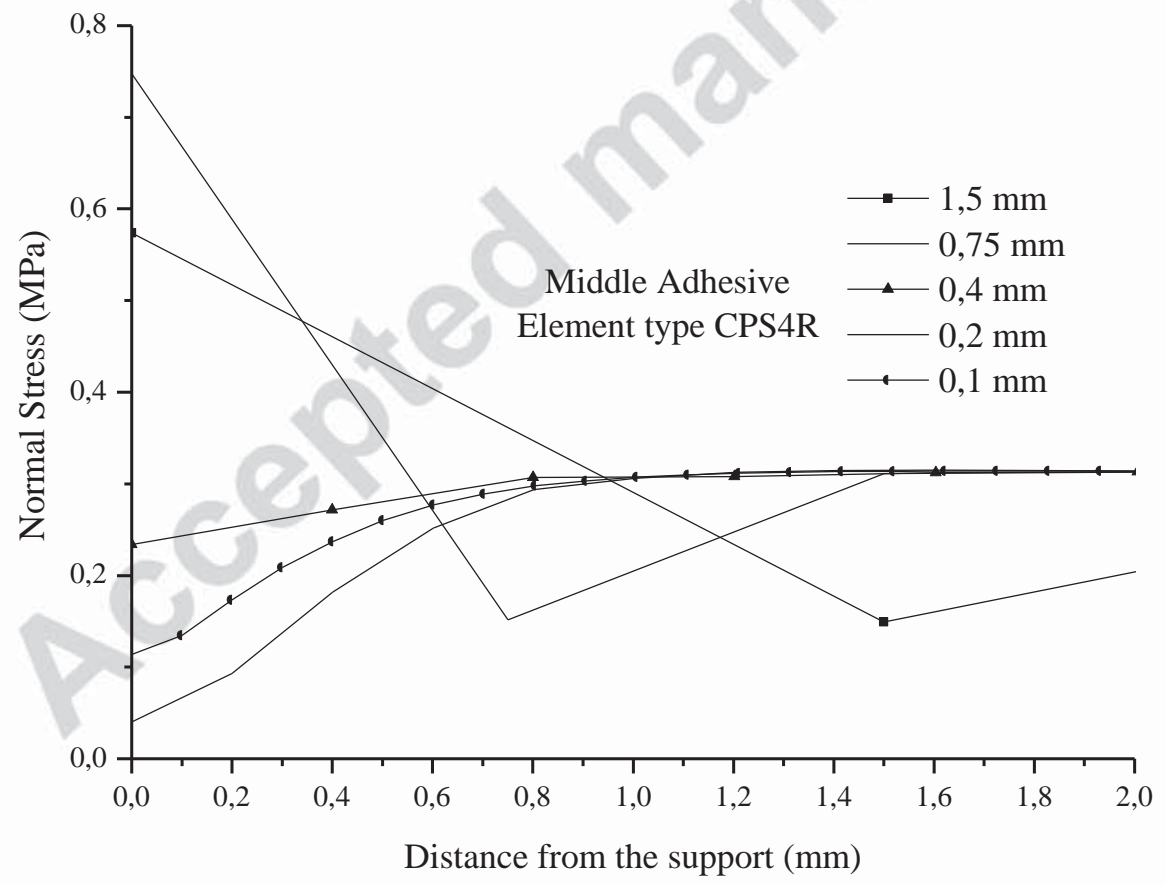

(b) 


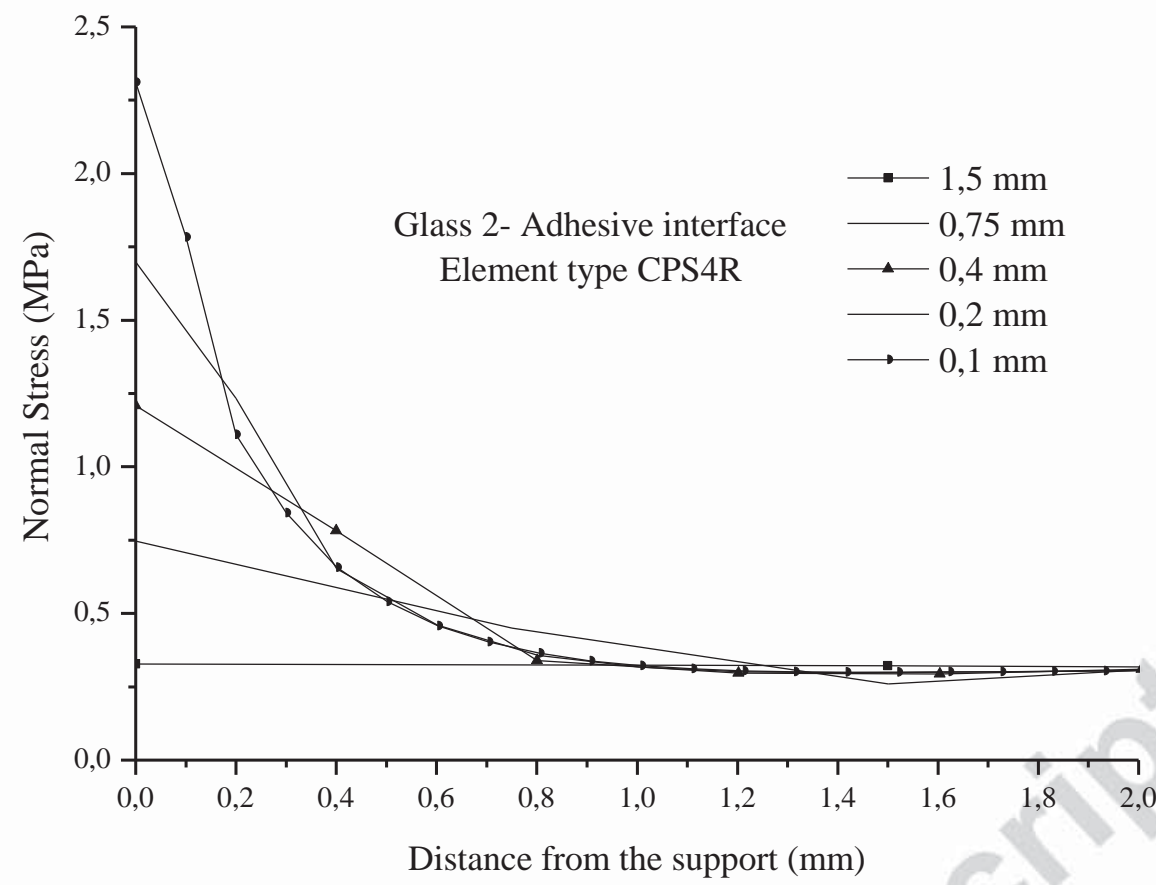

(c)

Fig.8. Interfacial transversal normal stress with respect to the distance from the support for various minimal finite elements sizes (a) at the upper glass-adhesive interface, (b) at the midadhesive section, (c) at the lower glass-adhesive interface.

The advantage of simple closed-form solutions, obtained in section 2, is that they lead to relatively simple closed-form expressions for interfacial stresses. However, a complex variation of the interfacial stresses through the adhesive layer cannot be captured by an analytical way. All these misadvantages can be avoided by a rigorous FE analysis. Based on this convergence study, a minimum element size of $0.2 \mathrm{~mm}$ has been selected. Indeed, the use of even smaller elements leads to very small localized differences in shear interfacial stresses. $0.4 \mathrm{~mm}$ could even be chosen for an accurate prediction of shear stresses at the two glass-adhesive interfaces but at the mid-adhesive section a minimum size of $0.2 \mathrm{~mm}$ is required. The differences are larger for normal interfacial stresses, but the size of $0.2 \mathrm{~mm}$ seems to be a good compromise between accuracy of the results and the number of degrees of freedom (that is to say the timeconsumption of the computation).

Using these mesh considerations, the model contains 130458 elements and 134400 nodes.

The comparison of the values of the interfacial stresses obtained by the FEM with those obtained in an analytical way is provided in figures $9 \mathrm{a}$ and $\mathrm{b}$. 


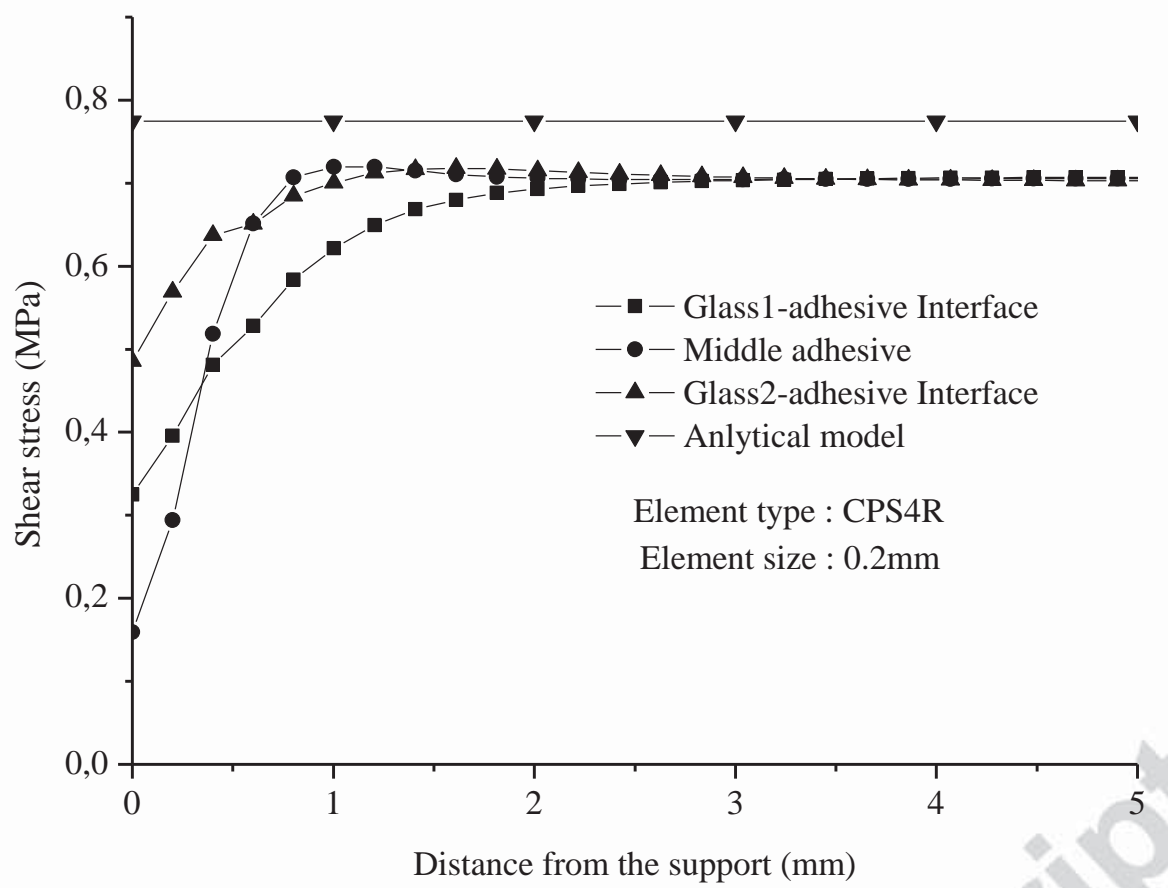

(a)

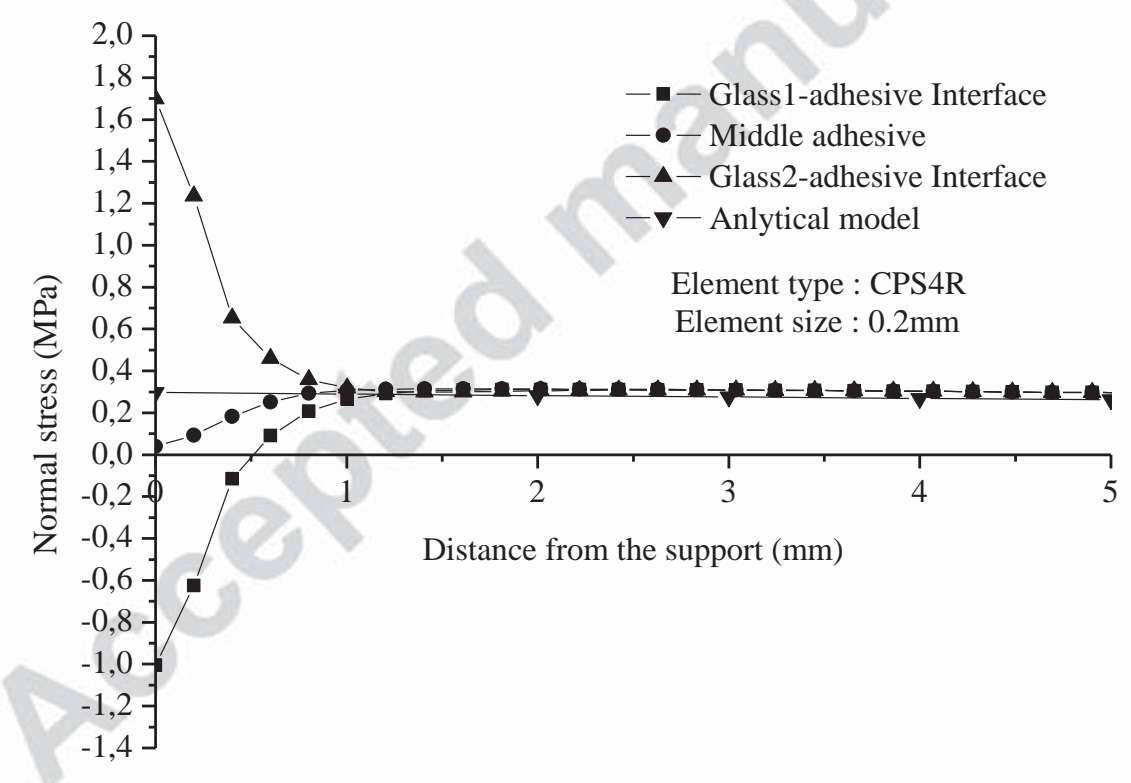

(b)

Fig.9. Comparisons between analytical and Finite Elements Methods for (a) interfacial shear stresses and (b) interfacial transversal normal stresses.

The first conclusion that can be drawn from this comparison is that numerical and analytical results tend to the same values and are generally close to one another, thus validating the preliminary modelling developments. Furthermore, from this analysis, it is clear that, in some 
cases, closed-form solutions obtained in section 2 can be considered as a good alternative to a FE analysis. For example, they only slightly overestimate interfacial shear stresses and can be used for a safe design. Furthermore, the closed-form solutions match very well interfacial stresses at the mid-adhesive section. However the interfacial normal stresses present a complex variation through the adhesive layer and, over a distance of about $1 \mathrm{~mm}$, the analytical results are quite underestimated which is problematic since adhesives are less resistant when subjected to normal stresses than when they undergo shear stresses.

Finally, to conclude on this sensitivity analysis, it is worth noting that, to numerically determine the load-deflection curve of a 2 panes laminated glass element, the mesh fineness pointed out in this section is unnecessary. But with a coarser mesh, debonding risks would be underestimated.

3.2 Influence of the interface debonding on the load-bearing capacity of a laminated glass element

It is now well known that the lamination enables to increase the redundancy and the robustness of a single glass plate. A horizontally layered glass plate submitted to a 3 points bending test develops a failure mechanism in several steps. Several experimental ([2],[40]) or numerical [21]) observations relate this mechanism. When the maximal principal stress reaches the tensile strength of the material at the bottom of the lower plate, a crack appears and propagates rapidly through the glass pane. The presence of the interlayer and of the second glass pane provides a residual resistance and prevents the structure from collapsing, as it would be obtained for a single glass pane, and ensuring thus a certain amount of redundancy. The interlayer acts as a reinforcement ensuring thus even more the structural safety of the structure. The applied force resulting from the imposed displacement continues then to increase. Achieving the tensile strength then leads to the final rupture of the structure.

It appears thus that the interlayer plays a crucial role in this post-cracking behavior and then, as a consequence, the structural integrity of a laminated glass element may be challenged by risks of debonding of the glass panes. Such a phenomenon may be due not only by the failure of the interlayer but also by the loss of adhesion. This new part of the paper investigates this last point.

\subsubsection{Description of a reference experimental procedure to assess the glass/interlayer adhesion}

To quantify interlayer/glass adhesion, the Tension Adhesion Test, or Through Crack Tensile Test, is recommended [41]. In this experimental procedure, a laminated glass pane is firstly cracked in its center and along its width on both sides. Then, an in-plane force P or a displacement $U$ along the longitudinal axis of the pane is imposed at the ends of the laminated element, enabling thus to load the bond between the interlayer and the glass to determine finally 
its strength (Fig. $10 \mathrm{a}$ and b). This configuration is equivalent to the flexure adhesion test for large displacements, i.e a 3 points bending of a laminated glass pane cracked in its center [42].

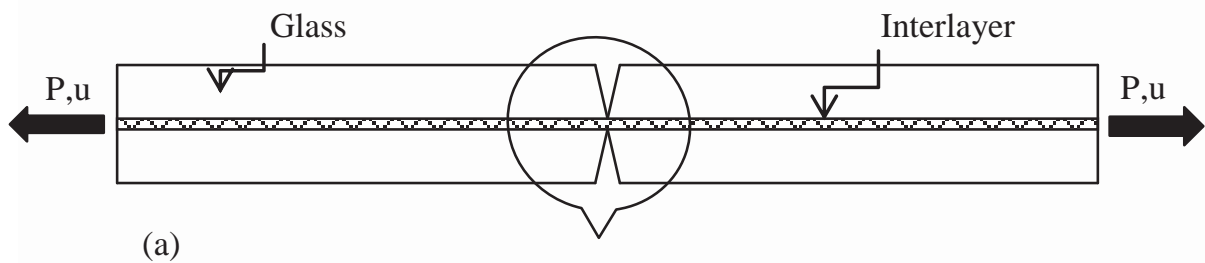

(a)

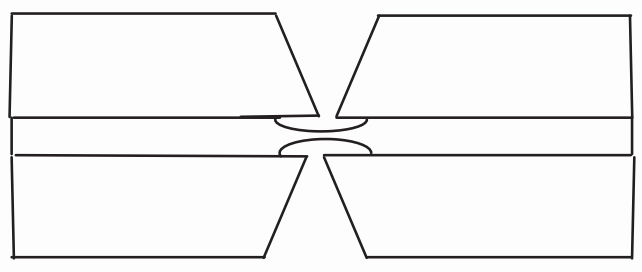

(b)

Fig.10. Tension adhesion test (a) and occurrence of debonding near the crack tip (b)

In this study, the experimental campaign performed in [24] is considered. A polyvinyl-butyral (PVB) interlayer manufactured by Monsanto Company is used with three different levels of adhesion, namely low, medium and high adhesion. The previous explained tests are conducted at room temperature. The displacement rate at the loading point is controlled and maintained at a constant value of $8.47 \times 10-6 \mathrm{~m} / \mathrm{s}$. The length and the width of the specimen are respectively $0.102 \mathrm{~m}$ and $5.08 \times 10^{-2} \mathrm{~m}$; the thickness of a single glass pane is $2.54 \times 10^{-3} \mathrm{~m}$. The two glass panes are identical. The load is recorded and load-displacement curves may be drawn. Near the crack tip, high normal and shear stresses in glass and interlayer lead to the debonding of the interface as shown schematically in figure $10 \mathrm{~b}$.

\subsubsection{Local debonding model}

In this part of the paper, it is proposed to connect the material points adjacent to the interface by two non-linear springs (Fig.11 a). The first one, referred as the shear spring in the following, acts in the tangential direction and results in the shearing of the interface, whereas the second one (called the normal spring in the following) governs its opening. Such modeling strategy is widely used in steel-concrete composite structures where the springs model the metallic connectors linking the concrete slab and the steel profile (see for example [42]).

The normal and shear springs are assumed to follow a cohesive crack model: when the yield force of the spring is reached, the force decreases linearly to zero leading to a softening 


\section{ACCEPTED MANUSCRIPT}

behavior (Fig.11 b). This choice is microscopically justified by the appearance of micro-cracks at the interface which progressively grow up until the coalescence into a single macro-crack and consequently the debonding along the interface. Elements SPRING2 in the Abaqus library are considered. Normal and shear behaviors are supposed to be uncoupled: pure normal separation by itself does not give rise to cohesive forces in the shear directions, and pure shear slip with zero normal separation does not give rise to any cohesive forces in the normal direction.

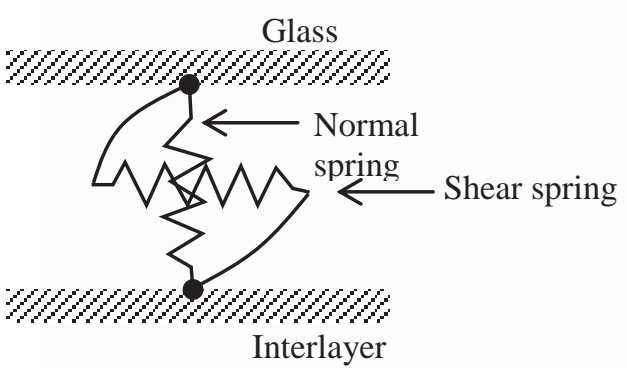

(a)

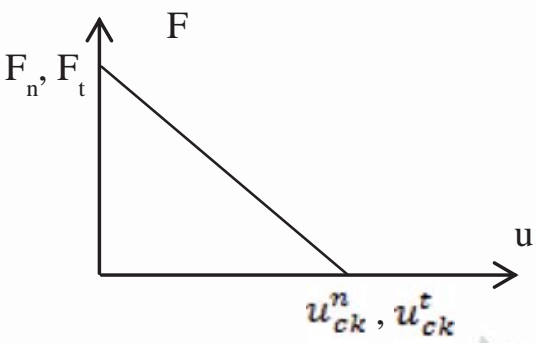

(b)

Fig.11. Normal and shear springs across the interface ad linking two adjacent points, one belonging to the glass and the other to the interlayer (a) and Cohesive crack model used for the interface debonding (b).

Shear and normal behaviors are assumed to be uncoupled. $F_{n}$ and $F_{t}$ stand for the maximal forces in normal and shear springs respectively, $u_{n k}^{n}$ and $u_{r k}^{t}$ are the cracking displacements in normal and shear springs respectively.

The values of the shear and normal yield forces, as well as those of the cracking opening and shearing displacements are the unknowns of the model and need to be identified on the basis of the experimental results. Moreover, as shown later, the debond length influences highly the whole load-displacement curve of the interface and may vary from an adhesion level to another. This parameter is thus another unknown of the model.

\subsubsection{Identification of the parameters of the model}

In this part of the paper, the FE general package Abaqus is used too. For symmetry reason, only a quarter of the laminated structure is analyzed (Fig.12). The mesh used is similar to the one pointed out in section 3.1: four-node linear quadrilateral plane stress elements are considered too and their minimum size is equal to $0.2 \mathrm{~mm}$. All the finite elements present an aspect ratio of 1:1. The mesh is composed of about 8300 nodes and 7600 elements. 
Fig.12. Mesh used to simulate the tension adpesion test. On the right, the boundary condition is

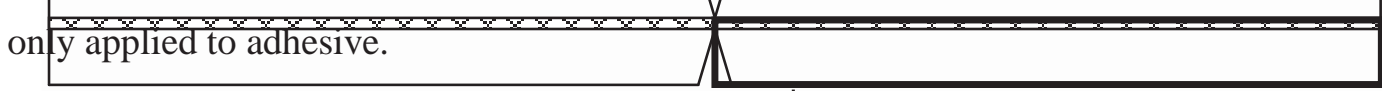

In the FEM simulation, plane strain elements arefconsidered for both the glass plane and the ing dosed displacement is not too large. It is also implicitly assumed that the failure mechanism is localized at the interface between the glass pane and the adhesive and consequently that this last one is not sufficiently loaded to enter in its hardening domain. The Young's modulus and the Poisson coefficient of glass are equal to respectively $70 \mathrm{GPa}$ and 0.22 . For the adhesive, the values identified in the experimental study [24] have been used: $\mathrm{E}=4 \mathrm{MPa}$ and $v=0.5$. Along the debond length, all adjacent nodes are linked by normal and shear springs as explained in the previous section. A displacement field is applied at the end of the laminated plate and the corresponding reaction force is obtained in order to draw the load-displacement curve.

It is obvious that an inverse analysis method would be very useful to identify precisely all the parameters of the springs mechanical behavior. Such a tool would be the topic of an upcoming research and has not been used in this study. The shear behavior of the springs influences significantly the load-displacement curve. The debond length has a significant effect on the second part of the curve. A too important length would result in the assessment of a horizontal asymptote resulting in a perfectly plastic overall behavior. That is why in practice $\mathrm{F}_{\mathrm{t}}, u_{r . k}^{t}$ and the debond length are first adjusted until a reasonable fit to the experimental data is obtained. Then $\mathrm{F}_{\mathrm{n}}$ and $u_{r k}^{n}$ are identified to get the best possible fit.

The agreement between the finite element simulation and the experimental data is shown in figure 13. A reasonably good fit is put into evidence. The various identified parameters are provided in Table 3. It is worth noting here that these parameters are only available for the PVB interlayer studied in this part of this work. In this table, as it is of prime practical importance, the maximal forces in the springs are converted in terms of adhesion strength. This can be done by keeping in mind that the springs are associated in series for the shear behavior and in parallel for the normal one. 


\section{ACCEPTED MANUSCRIPT}

Each of the adhesion levels may now be characterized by a fracture toughness. Data provided in

Table 3 lead to the following values: 159.75, 300.75 and $698.5 \mathrm{~N} / \mathrm{m}$ for respectively the low, medium and high adhesions.

Table 3. Identified constitutive parameters of the debonding model.

\begin{tabular}{|l|c|c|c|c|c|}
\hline $\begin{array}{l}\text { Adhesion } \\
\text { level }\end{array}$ & $\begin{array}{l}\text { Shear adhesive } \\
\text { strength (MPa) }\end{array}$ & $\begin{array}{c}\text { Normal } \\
\text { adhesive } \\
\text { strength (MPa) }\end{array}$ & $\begin{array}{c}\text { Shearing } \\
\text { cracking } \\
\text { disp. } u_{c k}^{\mathrm{t}} \\
(\mathrm{mm})\end{array}$ & $\begin{array}{c}\text { Opening } \\
\text { cracking } \\
\text { disp. } u_{c k}^{\mathrm{n}} \\
(\mathrm{mm})\end{array}$ & $\begin{array}{c}\text { Debond } \\
\text { length (mm) }\end{array}$ \\
\hline Low & 1.23 & 1.47 & 0.2 & 0.05 & 2.4 \\
\hline Medium & 1.65 & 1.47 & 0.32 & 0.05 & 2.4 \\
\hline High & 2.45 & 1.72 & 0.5 & 0.1 & 2 \\
\hline
\end{tabular}

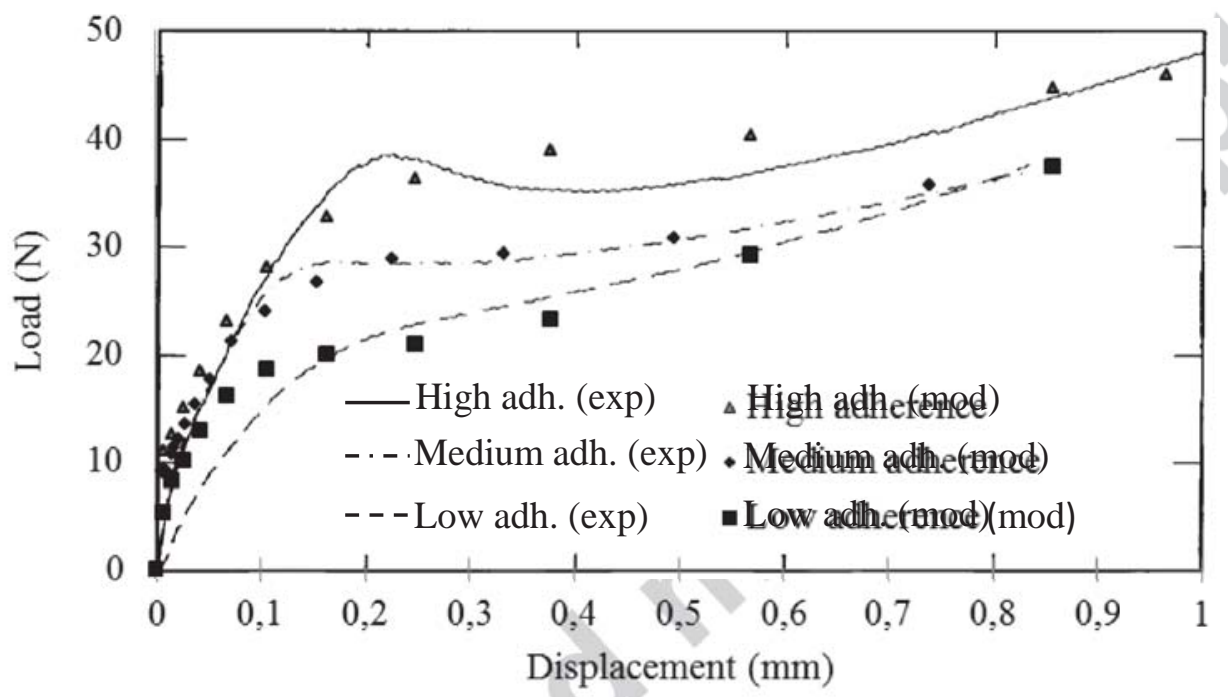

Fig. 13. Experimental results of Sha et al. 1997 [24] and their comparison with the modeling results obtained in the present study.

\subsubsection{Applications at the structural scale}

The local debonding model is now used to simulate the 3 point bending of the laminated glass plate presented in figure 10. A similar mesh, as the one retained in the identification numerical procedure, is considered and a minimal element size of $0.2 \mathrm{~mm}$ is another time used. Due to symmetry reason only a half of the structure is investigated.

In this subsection, as we investigate the failure mechanism of the laminated structure, it was decided to consider the fracture behavior of glass. Glass is thus assumed to be brittle in tension. A smeared crack model, Hillerborg-type [36] is used to represent this tensile behavior. A Rankine criterion is used to detect crack initiation: this criterion states that "cracking" occurs 


\section{ACCEPTED MANUSCRIPT}

when the maximum principal stress reaches and exceeds the tensile strength of the material. Thus crack detection is based only on mode I facture considerations. A conservative value (20 $\mathrm{MPa}$ ) of the tensile strength is considered. ABAQUS then assumes that "cracks" are fixed and orthogonal to the direction of the maximum principal stress. The specification of the post-failure behavior needs to enter the post-failure stress as a tabular function of the displacement across the crack (instead of strain which can introduce mesh sensitivity) or, in an equivalent way, the value of the fracture energy $G_{F}^{I}$. $G_{F}^{I}$ represents the energy required to form a unit area of crack surface. This material property can be obtained thanks to the following LEFM formula:

$G_{F}^{I}=\frac{K_{I C}^{2}}{E}$

where $K_{I c}$ is the glass toughness $(0.75 \mathrm{MPa} / \mathrm{m})$ and $\mathrm{E}$ is the Young's modulus (70 $\mathrm{GPa}$ ). Consequently, $G_{F}^{I}=8 \mathrm{~N} / \mathrm{m}$ for silica-soda-lime glass.

On the other hand, the compression behavior of glass is assumed to be always linear elastic.

The interlayer material is assumed to be purely elastic and its Young's modulus is taken equal to $4 \mathrm{MPa}$ as in the study of Sha et al. [24].

The possibility of debonding before an allowable stress of $20 \mathrm{MPa}$ is reached at the bottom of the lower glass pane is first analyzed. A displacement is imposed on the top point of the symmetry plane and, to facilitate the convergence of the computation, 4 nodes around the opposite are pinned. Two series of normal and shear springs are used on the 2 interfaces between glass and adhesive near to the pin and at the symmetry plane. The values identified previously for the medium adhesion level are considered. Arc-length method is used.

Figure 14 presents the deformed mesh numerically determined when the allowable stress at the bottom of the plate is reached (displacement magnification factor: $\times 8$ ). Shear and normal debondings are put into evidence in the vicinity of the boundary condition. On the contrary, no obvious debonding seems to appear under the loading condition. However the comparison of the load-displacement curve with the one obtained with no debonding model of the interface reveals no difference (not shown here). 


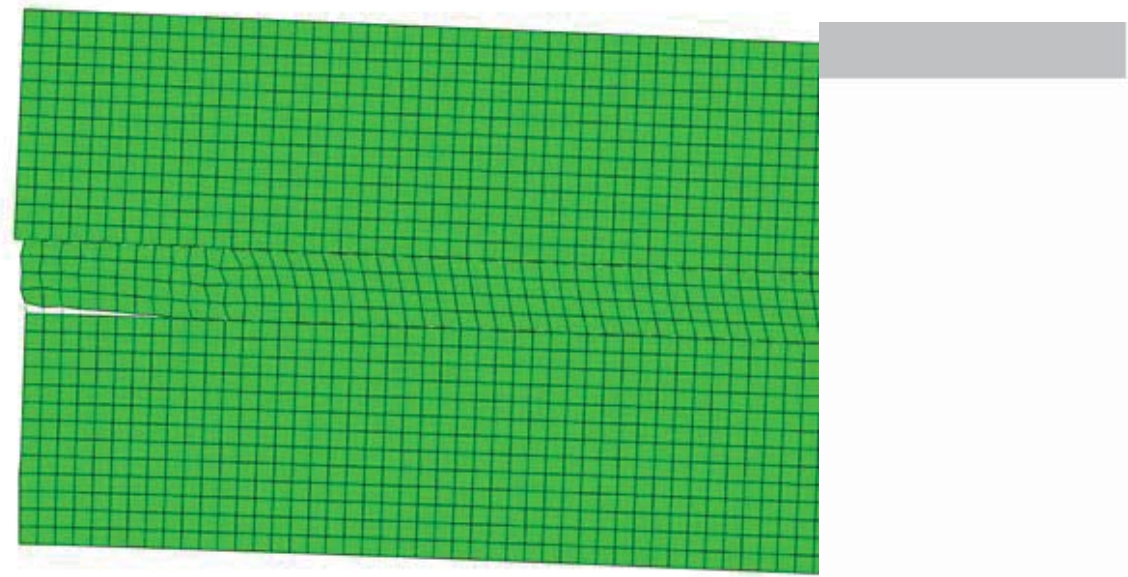

Fig.14. Occurrence of debonding near the boundary condition. A shearing and opening of the interface is put into evidence before the allowable stress is reached. (magnification factor: x8)

The second application concerns the redundancy of the structure once the lower pane is broken. To take into account the crack across this pane, the symmetry condition has only been imposed to the upper glass pane and to the interlayer. The same mesh and boundary conditions as in the previous application have been considered. A cohesive crack model with tension stiffening is used for glass, as in [38]. The tensile strength is assumed to be equal to $20 \mathrm{MPa}$ and the fracture energy to $8 \mathrm{~N} / \mathrm{m}$. Arc-length method is used too in this part of the study. The load-displacement curves with and without the presence of the springs at the interfaces between glass and PVB are drawn in figure 15. No visible redundancy decrease is put into evidence, and the maximal force that the structure is able to bear is the same in both cases. It appears thus that the debondings near the crack tip and in the vicinity of the pin have no influence on the load bearing capacity. These debondings do exist and are illustrated by figure 16 that presents the deformed mesh of the laminated element at the peak load. A shear debonding is put into evidence in the vicinity of the pin and near the crack tip, whereas a normal debonding appears mainly near the crack tip. The reason why the load bearing capacity remains unchanged is probably the tight localization of the debonding. If the debond length was higher, for example because of aggressive environmental conditions, the maximal load would probably change.

However it is worth noting here that this conclusion cannot be extrapolated to other loading cases. As for an example, such a debonding, together with a crack appearance, can influence the critical load of the structure (Ouyang et al. [39]).

Furthermore, contrary to the maximal force, the force-deflection curve presents some differences since the appearance of the debondings decreases slightly the slope of the curve just after the initiation of the crack in the upper glass layer. 


\section{ACCEPTED MANUSCRIPT}

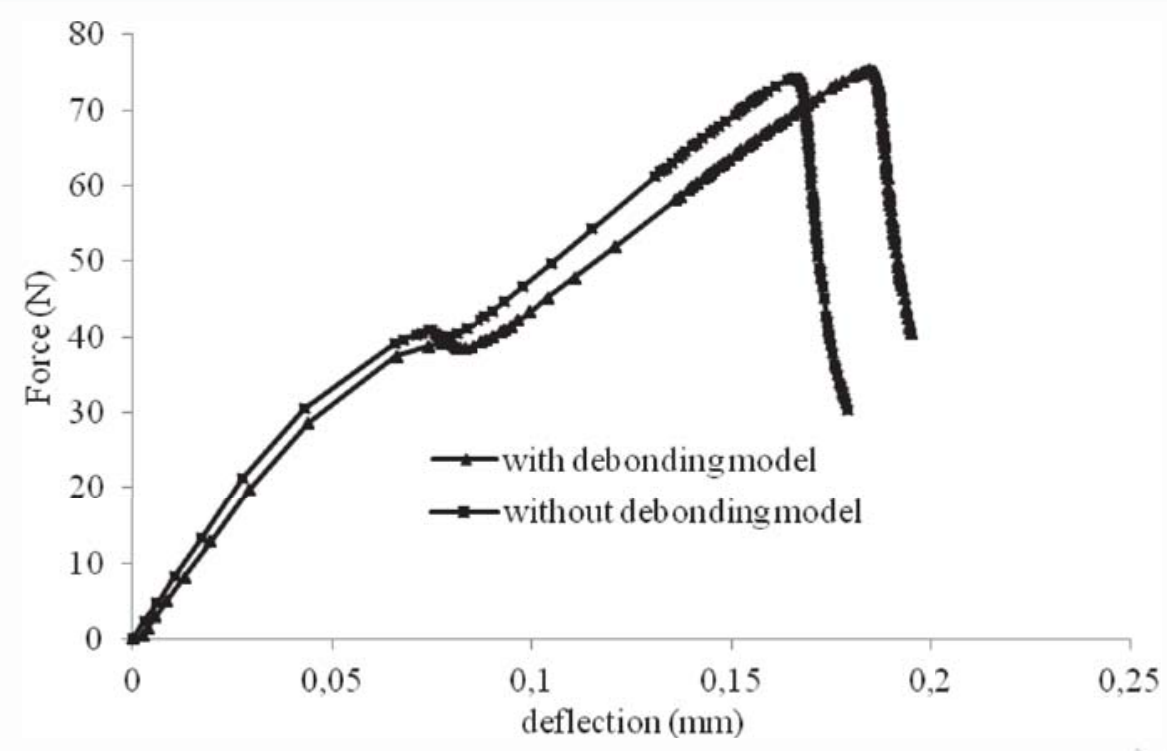

Fig.15. Residual flexural load-displacement curve once the lower glass plane is broken. No significant influence of the debonding on the load bearing capacity is put into evidence.

Fig.16. Deformed mesh of a horizontally laminated glass element submitted to a 3 point bending with an initial vertical crack completely through the lower glass pane

(displacement magnification factor: $\times 5$ ).

This paper investigates the behavior of a horizontally laminated glass element. A coupled analytical / numerical modeling is thus proposed.

A thoroughly theoretical study enables first to determine accurately the interfacial normal and shear stresses responsible for debonding risks and to analyze then the effect of some parameters/assumptions such as the shear-lag effect, the different curvatures between adherends and also the adhesive or the glass thicknesses. The first study enables also to calibrate a FE modeling presented in a second part. More particularly, an optimal mesh leading to consistent results with the analytical study is identified. The FE model may also obtain the complex variation of the interfacial stresses through the thickness, which reveals to be important in order 


\section{ACCEPTED MANUSCRIPT}

to not underestimate the debonding risks. In a second time, this computation is performed until the ultimate limit state of the structure.

Finally, a methodology to explicitly take into account a possible debonding between the panes is proposed. It consists to use normal and shear spring elements between adhesive and both glass panes combined with a cohesive crack model. The experimental work of Sha et al. [24] has been used to validate this methodology.

The main conclusions of this work are summarized below:

- The differential equations that govern the evolution of the shear and normal stresses in the adhesive layer are coupled. The general solution of the shear stresses allows to obtain the expression of the normal stresses. Concerning the theoretical assumptions that lead to these differential equations and therefore to the expression of the interfacial stresses, it appears that taking into account different curvatures between adherends leads to an increase by about $10 \%$ of the shear stresses whereas normal stresses are not influenced by this parameter. The shear-lag effect has no significant influence on the results. Concerning the geometrical parameters, it appears that glass thickness plays a crucial role on the evolution of both normal and shear stresses, in contrast to the adhesive thickness.

- $\quad$ The FE modeling reveals a failure mechanism of the horizontally layered glass element in several steps and an increased redundancy due to the presence of the interlayer and a second glass pane.

- A fracture toughness of the adhesion between glass and interlayer may be determined by inverse analysis based on Tension Adhesion Test. The debond length is a parameter of the model that may be characterized carefully. A laminated element composed of two glass panes may exhibit debonding in classical service conditions. This debonding does not reduce significantly the load bearing capacity and modifies only the slope of the force-deflection curve.

It is worth noting that this study has been performed in quasi-static conditions for a given load or displacement rate. Furthermore, no aggressive environmental conditions, for example change of temperature or humidity especially on the behavior of the interlayer and on the fracture toughness of the adhesion between glass and interlayer, have been considered. Future work will concern the extension of the analytical and numerical models to the consideration of these various cases. Concerning the interlayer behavior, temperature would certainly be a major issue to investigate. 


\section{ACCEPTED MANUSCRIPT}

It would also be interested to take into account initial pre-stresses state due to thermal tempering/heat strengthening processes such as the one modeled by [44-47] and which may modify the failure mechanisms.

\section{ACKNOWLEDGEMENT}

COST Action TU 0905 "Structural Glass - Novel Design Methods and Next Generation Products" is gratefully acknowledged for providing a valuable research network for this study.

\section{REFERENCES}

[1] Haldimann M., Luible A., Overend M. Structural Use of Glass. Structural Engineering Documents. Zurich: International Association for Bridge and Structural Engineering, 2008.

[2] Knoll F., Vogel T. Design for Robustness. Structural Engineering Documents. Zurich: International Association for Bridge and Structural Engineering, 2009.

[3] Fam A., Rizkalla S. Structural performance of laminated and unlaminated tempered glass under monotonic transverse loading. Construction and Building Materials 2006;20(9):761-768.

[4] Louter C, Belis J, Bos F, Veer F. Experimental investigation of the temperature effect on the structural response of SG-laminated reinforced glass beams. Engineering Structures 2010;32 (6):1590-1600.

[5] Louter C., Belis J., Veer F., Lebet J.-P. Structural response of SG-laminated reinforced glass beams; experimental investigations on the effects of glass type, reinforcement percentage and beam size. Engineering Structures 2012;36:292-301.

[6] Asik M. Z., Tezcan S. A mathematical model for the behavior of laminated glass beams. Computers and Structures 2005;83(21-22):1742-1753

[7] Galuppi L., Royer-Carfagni G. The effective thickness of laminated glass: Inconsistency of the formulation in a proposal of EN-standards. Composites Part B: Engineering 2013;55:109118.

[8] Ivanov I. Analysis, modelling, and optimization of laminated glasses as plane beam. International Journal of Solids and Structures 2006;43:6887-6907.

[9] Foraboschi P. Behavior and failure strength of laminated glass beams. Journal of Engineering Mechanics 2007; vol. 133(12):1290-1301. 


\section{ACCEPTED MANUSCRIPT}

[10] Foraboschi P. Analytical model for laminated-glass plate. Composites Part B: Engineering 2012; 43(5): 2094-2106

[11] Galuppi L., Manara G., Carfagni G.R. Practical expressions for the design of laminated glass. Composites Part B: Engineering 2013;4(1):1677-1688.

[12] Fröling M., Persson K. Computational Methods for Laminated Glass. Journal of Engineering Mechanics 2013;139(7):780-790.

[13] Smith S.T., Teng J.G. Interfacial stresses in plated beams, Engineering Structures 2001; 23(7):857-871.

[14] Tounsi A., Benyoucef S. Interfacial stresses in externally FRP plated concrete beams. International Journal of Adhesives 2007;27:207-215.

[15] Lau K.T., Dutta P.K., Zhou L.M., Hui D. Mechanics of bonds in a FRP bonded concrete beam. Composites Part B: Engineering 2001;32:491-502.

[16] Tsai M. Y., Oplinger D. W., Morton J. Improved theoretical solutions for adhesive lap joints. International Journal of Solids and Structures 1998;35(12):1163-1185.

[17] Tounsi A. Improved theoretical solution for interfacial stresses in concrete beams strengthened with FRP plate. International Journal of Solids and Structures 2006;43:4154-4174.

[18] Krour B., Tounsi A., Benyoucef S., Adda Bedia E. A. An improved closed-form solution to interfacial stresses in RC beams strengthened with a composite plate. Mechanics of Composite Materials 2010 46(3):331-340.

[19] Rabinovitch O., Frostig Y., High-order approach for the control of edge stresses in rc beams strengthened with frp strips, Journal of Structural Engineering, Vol. 127, No. 7, July, 2001.

[20] Tounsi A., Daouadji H., Benyoucef S., Adda Bedia E.A. Interfacial stresses in FRP-plated RC beams: Effect of adherend shear deformations. International Journal of Adhesion and Adhesives 2009;29(4):343-351.

[21] Bernard F., Krour B., Benyoucef S., Fahsi B. Development of a coupled analyticalnumerical procedure to determine the redundancy of a laminated glass structure. In: Proceedings of the COST Structural Glass Conference. Poreč (Croatia), April, 2013. p.391-403.

[22] Belis J., Depauw J., Callewaert D., Delincé D., Van Impe R. Failure mechanisms and residual capacity of annealed glass/SGP laminated beams at room temperature. Engineering Failure Analysis 2009; 16:1866-1875 


\section{ACCEPTED MANUSCRIPT}

[23] Overend M., Nhamoinesu S., Watson J. The structural performance of bolted and adhesively bonded joints in glass structures. ASCE Journal of Structural Engineering, 2013;139

[24] Sha, Y., Hui, C.Y., Kramer, E.J., Garrett, P.D. \& Knapczyk J.W. 1997. Analysis of adhesion and interface debonding in laminated safety glass. Journal of Adhesion Science and Technology 11 (1): 49-63.

[25] Williams M.L., 1952, Stress singularities resulting from various boundary conditions in angular corners of plates in extension. Journal of Applied Mechanics 1952;19:526-528.

[26] Williams M.L., 1959. The stresses around a fault or crack in dissimilar media. Bulletin of the Seismological Society of America 1952;49:199-204.

[27] Adams R.D., Peppiatt N.A., Effects of Poisson's ratio strains in adherend on stresses of an idealized lap joint. J. Strain Anal. 1973;8:134-139.

[28] Adams R.D., Davies R., Strength of joints involving composites. J. Adhesion 1996;59:171182.

[29] Gonçalves J.P.M., de Moura M.F.S.F., de Castro P.M.S.T., A three-dimensional finite element model for stress analysis of adhesive joints. Int. J. Adhes. Adhes. 2002;22:357-365 (2002)

[30] Adams R.D., Comyn J., Wake W.C., Structural Adhesive Joints in Engineering, 2nd edn. (Chapman \& Hall, London, 1997)

[31] Adams R.D., Davies R., Strength of lap shear joints, in The Mechanics of Adhesion, ed. by D.A. Dillard, A.V. Pocius (Elsevier, Amsterdam, 2002)

[32] Zhang L, Teng JG. Finite element prediction of interfacial stresses in structural members bonded with a thin plate. Engineering Structures 2010;32:459-471.

[33] Krour B., Bernard, F., Tounsi A. Fibers orientation optimization for RC beam strengthened with a CFRP bonded plate: a coupled analytical-numerical investigation. Engineering Structures 2013;56:218-227.

[34] Krour B. Méthode améliorée pour la réduction des contraintes de décollement dans les poutres en béton armé renforcées par des plaques en composites. PhD thesis of INSA Rennes and Univ. of Sidi Bel Abbes, 2012.

[35] Louter C., Nielsen J.H. Numerical analyses of the effect of SG-interlayer shear stiffness on the structural performance of reinforced glass beams. In: Proceedings of the COST Structural Glass Conference. Poreč (Croatia), April, 2013. P.405-412. 


\section{ACCEPTED MANUSCRIPT}

[36] Hillerborg A., Modeer M., Petersson P.E. Analysis of crack formation and crack growth in concrete by means of fracture mechanics and finite elements. Cement and Concrete Research 1976;6:773-782.

[37] Timmel M., Kolling S., Osterrieder P., Du Bois P. A finite element model for impact simulation with laminated glass. Int. Journal of Impact Engineering 2007;34:1465-1478.

[38] Bernard F., Fahsi B., Krour B. How to model glass failure in load-bearing glass elements? A discussion based on analytical, numerical and experimental considerations. In: Proceedings of the Challenging Glass Conference 3. Delft (The Netherlands), June, 2012. p.405-417.

[39] Ouyang Z., Li G., Nonlinear interface shear fracture of end notched flexure specimens, International Journal of Solids and Structures 2009;46:2659-2668.

[40] Biolzi L., Cattaneo S., Rosati G. Progressive damage and fracture of laminated glass beams. Construction and Building Materials 2010;24(4):577-584.

[41] Delincé D., Experimental approaches for assessing time and temperature dependent performances of fractured laminated safety glass, PhD thesis, Technical University of GhentBelgium (2014)

[42] Bernard F., Krour B., Benyoucef S., FahsiB., Numerical analysis of the debonding of the adhesive interlayer in a laminated glass plate, In: Proceedings of the Challenging Glass 4 \& COST TU 0905 final conference. Lausanne (Switzerland), February, 2014. p.491-497.

[43] Lim S., Bernard F. Parametric Study of Bonded Connection in Composite Structures through the FE Modeling of Push-Out Test. Procedia Engineering 2011;14: 1455-1462

[44] Nielsen J. H., Olesen J. F., Poulsen P.N., Stang H. Simulation of residual stresses at holes in tempered glass: a parametric study. Materials and Structures 2010;43(7):947-961.

[45] Schneider J. Glass Strength in the Borehole Area of Annealed Float Glass and tempered Float Glass. Research in Architectural Engineering Series 2007;1:157-167.

[46] Bernard F., Daudeville L., Gy R. Finite element computation of residual stresses near holes in tempered glass plates. Glass Technology 2002 ;43C:290-295.

[47] Daudeville L., Bernard F., Gy R. Residual stresses near holes in tempered glass plates. Material Science Forum 2002;404-407:43-48. 